\title{
NCCN Task Force Report: Molecular Markers in Leukemias and Lymphomas
}

Jerald P. Radich, MD; Andrew D. Zelenetz, MD, PhD; Wing C. Chan, MD; Carlo M. Croce, MD; Myron S. Czuczman, MD; Harry P. Erba, MD, PhD; Sandra J. Horning, MD; Jane Houldsworth, PhD; B. Douglas Smith, MD; David S. Snyder, MD; Hema M. Sundar, PhD; Meir Wetzler, MD; and Jane N. Winter, MD

\begin{abstract}
Key Words
Molecular markers, minimal residual disease, gene expression profiling, microRNAs, chronic myelogenous leukemia, non-Hodgkin's lymphoma, acute leukemias, targeted therapies, tyrosine kinase inhibitors, imatinib, rituximab, PCR, RT-PCR, BCR-ABL, kinase domain mutations, CML stem cells
\end{abstract}

\begin{abstract}
The introduction of targeted therapies has revolutionized treatment and improved outcomes in patients with leukemias and lymphomas. However, many patients experience relapse caused by the persistence of residual malignant cells. Cytogenetic and molecular techniques are increasingly being used to assess and quantify minimal residual disease (MRD). The emergence of advanced technologies has led to the discovery of multiple novel molecular markers that can be used to detect MRD and predict outcome in patients with leukemias and lymphomas. Gene expression signatures that predict clinical outcomes in patients with non-Hodgkin's lymphoma have been identified. In chronic myelogenous leukemia, molecular monitoring has become more important in assessing response and detecting resistance to therapy. In acute leukemias, several new markers have shown potential in prognostication and monitoring treatment. In leukemias and lymphomas, microRNAs have been identified that may be useful in diagnostics and prognostication. To address these issues, the National Comprehensive Cancer Network (NCCN) organized a task force consisting of a panel of experts in leukemia and lymphoma to discuss recent advances in the field of molecular markers and monitoring MRD. (JNCCN 2009;7[Suppl 4]:1-34)
\end{abstract}

\section{Overview}

Oncogenesis is complex and impacts diverse cellular processes, such as cell signaling, cell cycle, differentiation, and programmed cell death, and the tumor microenvironment. Molecular markers (proteins, cDNA, mRNA, or microRNA) reflect these perturbations and can be identified in tumor tissue, lymph nodes, bone marrow, peripheral blood, or other bodily fluids. Within malignant cells, molecular markers can be expressed either directly or indirectly through various mechanisms, such as activation of oncogenes, inactivation of tumor suppressor or DNA repair genes, activation of anti-apoptotic genes, or inactivation of pro-apoptotic genes. ${ }^{1}$ Because molecular markers are often associated with clinical prognosis, their measurement can be useful in clinical management to estimate a patient's chance of survival. Furthermore, molecular markers help identify individuals who are unlikely to benefit from standard therapies and therefore may choose to pursue investigational alternatives.

In hematologic malignancies, dysregulation of gene expressions occur predominantly through 2 mechanisms: ${ }^{2}$ 1) reciprocal translocations between chromosomes, leading to the formation of fusion genes and corresponding chimeric proteins; and 2) genomic rearrangements juxtaposing proto-oncogenes with immunoglobulin heavy chain (IgH) or T-cell receptor (TCR) genes, resulting in the dysregulated expression of structurally normal or truncated proteins. The best example of the former mechanism is the formation of BCR-ABL fusion gene and its fusion protein $\mathrm{p} 210$, resulting from the $t(9 ; 22)$ translocation in patients with chronic myelogenous leukemia $(\mathrm{CML})$. Examples of the latter mechanism include $t(14 ; 18)$ translocation involving BCL2 and IgH genes in follicular lymphoma and some diffuse large B-cell lymphoma (DLBCL), and $\mathrm{t}(11 ; 14)$ translocation involving BCL1 and $\mathrm{IgH}$ genes in mantle cell lymphoma (MCL). ${ }^{3}$ Other genetic abnormalities, such as chromosomal deletions and amplifications, result in gene expression alterations that may be used as molecular markers.

Although recent advances in treatment options have improved outcomes, currently available therapies 
are not curative in many patients with leukemia and lymphoma. Disease often relapses because of the persistence of low numbers of malignant cells that were not eradicated by previous therapies. Disease that is undetectable using conventional methods is referred to as minimal residual disease (MRD). MRD detection during or subsequent to treatment using reliable molecular markers is important because it provides biologic insight into the natural history of the disease. MRD status may theoretically allow early intervention with more effective treatment options, which may translate into improved outcome (e.g., prolonged time-to-progression). ${ }^{4-6}$ Recent clinical studies have shown that MRD eradication using new treatment modalities has significantly improved the duration of response and long-term survival in patients with hematologic malignancies.

Some molecular markers are anticipated to be critical for maintenance of the malignancy and would be potential targets for the development of novel treatment strategies. These targeted therapies may significantly improve the outcomes of patients with less treatment-related toxicity, leading to an era of individualized medicine. ${ }^{1}$ Molecular markers can also help identify subgroups of patients with similar risk profiles that are important in evaluating the effectiveness of therapy. Furthermore, molecular marker profiles may define which patients are eligible for treatment uniquely tailored to their particular disease biology.

Many molecular markers have been identified over the years through careful study of tumor biology. The emergence of novel genome-wide technologies has greatly accelerated the identification of molecular markers associated with the underlying biology of hematologic malignancies and prognostic importance. ${ }^{7}$ Molecular markers are increasingly being used as measures of response in clinical trials. ${ }^{8}$ Molecular markers associated with prognosis have also been used increasingly to stratify prospective randomized trials to ensure balanced assignment of patients according to risk group to the different treatment arms. Prognostic molecular markers facilitate the comparison of results from different clinical trials through characterizing different patient populations according to risk.

This report focuses on the methods used for identifying molecular markers and detecting MRD, their prognostic significance, and practical issues regarding their incorporation into routine clinical practice for leukemias and lymphomas, as discussed at the meeting on November 17, 2008.

\section{Molecular Markers in CML}

CML is characterized by the presence of the Philadelphia chromosome ( $\mathrm{Ph}$ chromosome) resulting from $t(9 ; 22)$. This translocation leads to the fusion of the BCR gene on chromosome 22 and the $A B L$ gene located on chromosome 9. ${ }^{9} \mathrm{CML}$ has classically been categorized as 3 different phases (chronic, accelerated, and blast) based on clinical and laboratory findings. However, gene expression profiling (GEP) suggests that the bulk of genetic changes in progression occur during transition from chronic to accelerated phase. ${ }^{10}$ Untreated chronic phase CML (fortunately now rare) will eventually progress to advanced phase disease in 3 to 5 years. ${ }^{11}$

Imatinib is the standard first-line therapy for patients newly diagnosed with chronic phase CML, based on its successful induction of durable responses in most patients. ${ }^{12-15}$ However, some patients with chronic phase disease either have primary resistance to imatinib or develop resistance, typically from the acquisition of point mutations in the $A B L$ tyrosine kinase domain of the BCR/ABL gene. Once disease progresses to advanced phase, responses to imatinib are far less frequent than in the chronic phase, and are not generally durable. ${ }^{16}$ More potent tyrosine kinase inhibitors (TKIs), such as dasatinib and nilotinib, have been effective in patients with imatinibresistant or -intolerant chronic phase CML. ${ }^{17,18}$

A better understanding of the mechanisms of disease progression and resistance to TKIs might lead to the development of curative treatment options for patients with CML. MRD monitoring and mutational analysis during the course of treatment are essential for timely implementation of treatment interventions to overcome resistance or prevent disease progression. ${ }^{19,20}$

\section{Monitoring Disease Response in CML}

Given that all cases of CML harbor the Ph chromosome (and thus, the BCR-ABL gene), sensitive monitoring can be used to establish treatment response. This section briefly summarizes methods for monitoring the most clinically significant treatment milestones for patients with CML undergoing TKI therapy. Hematologic Response: Complete hematologic re- 
sponse (CHR) is defined as complete normalization of blood counts with no immature blood cells; leukocyte count less than $10 \times 10^{9} / \mathrm{L}$; platelet count less than $450 \times 10^{9} / \mathrm{L}$; and lack of splenomegaly. Partial hematologic response indicates the presence of immature blood cells; platelet count less than $50 \%$ of pretreatment count but more than $450 \times 10^{9} / \mathrm{L}$; or persistent splenomegaly (but $<50 \%$ of pretreatment).

Most patients will experience CHR at 3 months after initial treatment with imatinib. If no CHR occurs at 3 months, patient compliance to imatinib therapy should be evaluated. Treatment interruptions and non-adherence to imatinib are associated with a lower probability of achieving cytogenetic or molecular response. Bone marrow cytogenetics should be repeated to confirm the diagnosis of chronic phase CML.

Cytogenetic Response: Cytogenetic response is determined by the decrease in the number of $\mathrm{Ph}$-positive metaphases, using conventional cytogenetic analysis (CGA) or fluorescence in situ hybridization (FISH; Table 1). ${ }^{21-24}$ Complete cytogenetic response $(\mathrm{CCyR})$ indicates that there are no Ph-positive metaphases. Partial cytogenetic response indicates that $1 \%$ to $35 \%$ of cells still have $\mathrm{Ph}$-positive metaphases. Major cytogenetic responses (MCyR) include both CCyR and partial cytogenetic responses. However, these categories are only relevant if at least 20 metaphases are evaluated.

Cytogenetic response is an important prognostic factor in CML treatment. Results from the International Randomized Study of Interferon Versus STI571 (IRIS) trial showed that CCyR is associated with less risk for events such as progression to advanced phases of CML and loss of hematologic and cytogenetic responses. ${ }^{25}$ At median follow-up of 60 months, progression-free survival was better for patients who experienced CCyR or partial cytogenetic response at 12 months than for those who did not have a MCyR at 12 months (97\%, 93\%, and 81\%, respectively; Figure 1A). ${ }^{25}$ The updated results also confirmed that overall and event-free survival rates at 6 years were significantly better for patients who experienced a CCyR at 6,12 , and 18 months and thereafter. ${ }^{26}$

After 1 year of imatinib therapy, de Lavallade et al. ${ }^{27}$ also identified cytogenetic response as the major prognostic factor for overall and progression-free survival. In the retrospective analysis of data from phase II studies of dasatinib in patients with imatinib-resistant chronic phase CML, progression-free survival was better for those who began taking dasatinib after losing MCyR on imatinib than for those who received dasatinib after loss of hematologic response. ${ }^{28}$ Although not a randomized trial of early versus late intervention for the loss of imatinib response, this analysis suggests that cytogenetic monitoring and early detection of relapse may improve outcomes in patients with imatinib-resistant chronic phase CML.

Early cytogenetic response to second-generation TKIs can also predict survival and guide subsequent therapy. Tam et al. ${ }^{29}$ examined this issue in patients with chronic phase CML receiving nilotinib or dasatinib after imatinib failure. After 12 months of treatment, patients experiencing MCyR had a significant survival advantage over those with minor cytogenetic response or CHR. Estimated 1-year progression to accelerated or blast phase were also significantly different between the groups (3\% vs. $17 \%$, respectively). Similar observations were made in a recent analysis of pooled clinical trial data of dasatinib treatment in patients with imatinib-resistant/intolerant CML. ${ }^{30}$ Cytogenetic response at 12 months was highly predictive of progression-free survival at 24 months, but did not have any effect on overall survival. These results suggest that patients experiencing no cytogenetic response at 3 or 6 months after treatment with dasatinib or nilotinib may be considered for alternative therapies.

Molecular Response: Molecular response is measured by the decrease in the BCR-ABL transcript levels in the peripheral blood or bone marrow using reverse transcription polymerase chain reaction (RT-PCR; Table 1). ${ }^{31-34}$ Major molecular response (MMR) indicates a 3-log reduction or greater of BCR-ABL chimeric mRNA. Complete molecular response occurs when no BCR-ABL chimeric mRNA is detectable.

Several studies have reported the prognostic significance of molecular response as reviewed by Jabbour et al. ${ }^{35}$ In the IRIS trial, the estimated progression-free survival rate at 24 months was $100 \%$ for patients with CCyR and at least a 3-log reduction in the BCR-ABL transcript level at 12 months, compared with $95 \%$ for those with CCyR and a BCR-ABL reduction of less than 3-log at 12 months (Figure 1B). ${ }^{25}$ Press et al. ${ }^{36}$ also showed that failure to achieve at least a $2-\log$ reduction in BCR-ABL mRNA at the time of CCyR or a 3-log reduction any time thereafter is an independent prognostic factor for progression-free survival. In a recent report, Press 
NCCN Task Force Report

\begin{tabular}{|c|c|c|c|c|}
\hline Test & Target & Tissue & Sensitivity (\%) & Comments \\
\hline CGA & Ph chromosome & BM & $1-10$ & $\begin{array}{l}\text { - Confirm diagnosis of CML } \\
\text { - Detects karyotypic abnormalities other } \\
\text { than Ph chromosome (i.e., clonal evolution) } \\
\text { - Gold standard for determination of } \\
\text { cytogenetic response }\end{array}$ \\
\hline $\begin{array}{l}\text { FISH } \\
\text { (interphase or } \\
\text { hypermetaphase) }\end{array}$ & $\begin{array}{l}\text { Juxtaposition of } \\
B C R \text { and } A B L\end{array}$ & $\mathrm{~PB}$ and $\mathrm{BM}$ & $0.5-5$ & $\begin{array}{l}\text { - Confirm diagnosis of CML } \\
\text { - Detects Ph-positive cells, which are } \\
\text { undetectable using CGA } \\
\text { - Routine monitoring of cytogenetic } \\
\text { response in patients who are clinically } \\
\text { stable } \\
\text { - Routine measurement of minimal residual } \\
\text { disease } \\
\text { - Useful until Ph chromosome levels are } \\
<5 \%-10 \% \text {, but not useful for monitoring } \\
\text { further reduction in Ph-chromosome levels } \\
\text { - Not validated in IRIS trial }\end{array}$ \\
\hline RT-PCR & $B C R-A B L$ mRNA & $\mathrm{PB}$ and $\mathrm{BM}$ & $0.0001-0.001$ & $\begin{array}{l}\text { - Most sensitive method for the } \\
\text { measurement of minimal residual disease } \\
\text { - Useful for monitoring of molecular } \\
\text { response after the patient has achieved } \\
\text { CCyR } \\
\text { - Strong correlation between results } \\
\text { obtained from PB and BM, allowing } \\
\text { minimal residual disease monitoring } \\
\text { without the need to obtain BM aspirations } \\
\text { - Techniques and use of various internal } \\
\text { controls are different among institutions } \\
\text { and laboratories } \\
\text { - Assay and reporting have not been } \\
\text { standardized }\end{array}$ \\
\hline
\end{tabular}

Abbreviations: BM, bone marrow; CCyR, complete cytogenetic response; CGA, conventional cytogenetic analysis; CML, chronic myelogenous leukemia; FISH, fluorescence in situ hybridization; PB, peripheral blood; RT-PCR, reverse transcription polymerase chain reaction.

et al. ${ }^{37}$ also reported that a minimal half-log increase in the BCR-ABL or loss of MMR predicts shorter relapse-free survival in patients who were in complete cytogenetic remission on imatinib therapy (Figure 2).

Molecular responses also predict the duration of CCyR. Cortes et al. ${ }^{38}$ reported that major and complete molecular remissions were associated with more durable cytogenetic responses. A significantly lower portion of patients ( $5 \%$ with MMR and $4 \%$ with complete molecular remission) lost the CCyR, compared with 37\% who did not reach these levels of molecular response.

The GIMEMA study group reported similar findings. ${ }^{39}$ In patients who received imatinib after interferon failure, those who attained MMR at 12 months and those who experienced a MMR at first $\mathrm{CCyR}$ remained in complete cytogenetic remission for a longer period. Only 3\% of these patients lost their CCyR compared with $30 \%$ of patients who did not attain this level of molecular response. ${ }^{39}$

Although early molecular response is a predictor of durable long-term remission rates and progressionfree survival, some studies suggest that it does not predict a long-term survival advantage. In patients experiencing CCyR at 12 or 18 months, achievement of molecular response at these points did not affect progression-free or overall survival. ${ }^{27,40}$ Marin et al. ${ }^{41}$ also confirmed that patients who did not have an MMR at 18 months had a higher chance of losing CCyR, this did not translate into a difference in progression-free survival.

Kantarjian et al. $^{42}$ recently analyzed the significance of rising BCR-ABL transcript levels as deter- 


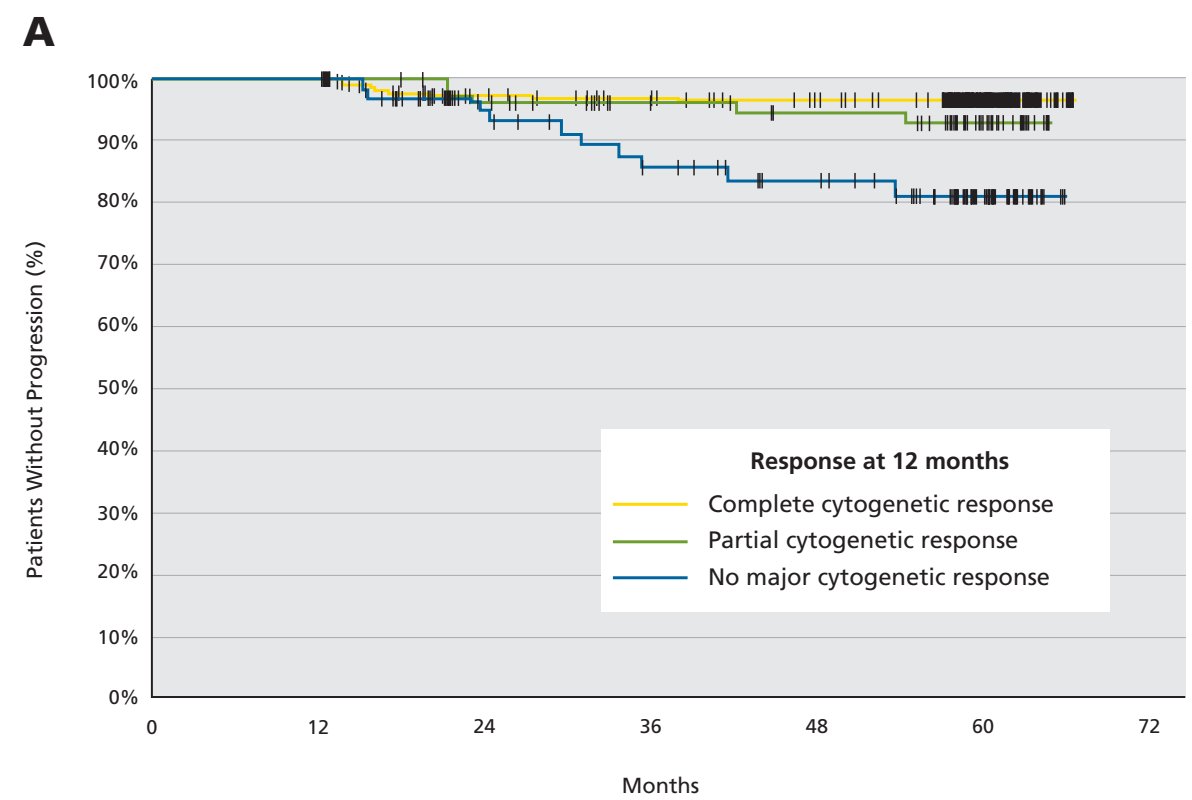

B

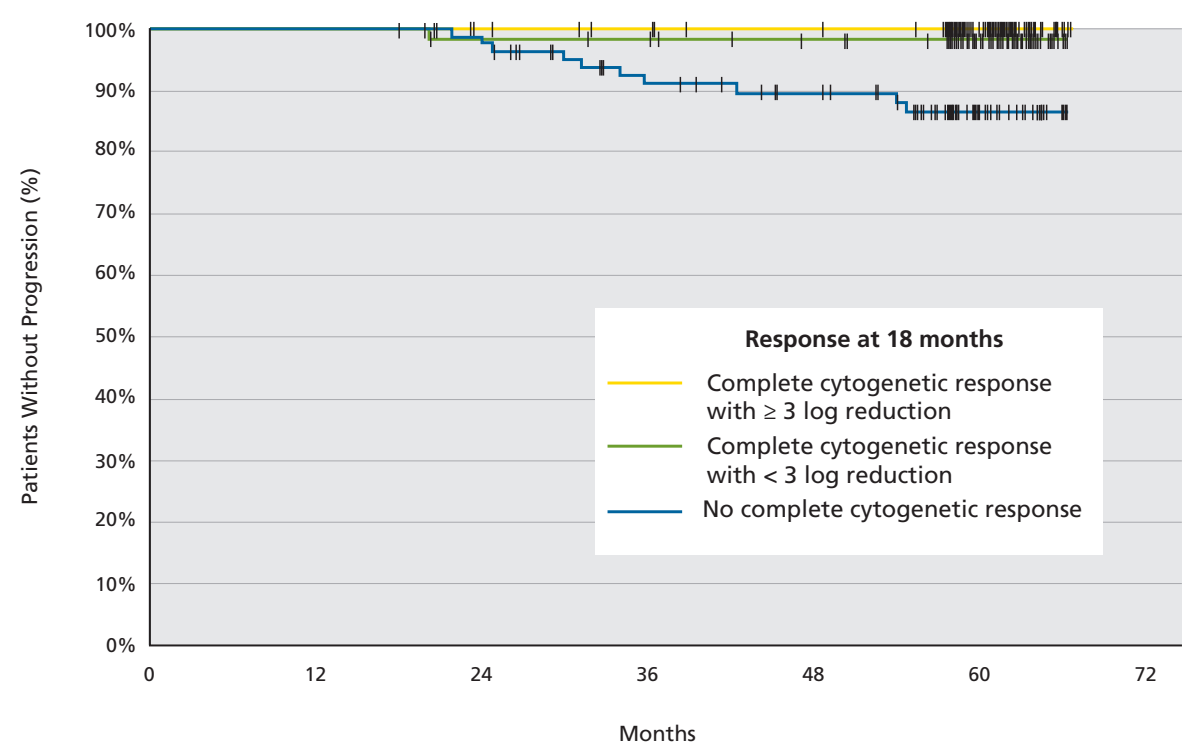

Figure 1 Rate of progression to the accelerated phase or blast crisis based on cytogenetic response after 12 months or molecular response after 18 months of imatinib therapy.

From Druker BJ, Guilhot F, O'Brien SG, et al. Five-year follow-up of patients receiving imatinib for chronic myeloid leukemia. N Engl J Med 2006;355:2413; with permission.

mined with quantitative RT-PCR. Of 258 patients with chronic phase CML on imatinib therapy, 116 in CCyR experienced an analytically significant increase in BCR-ABL transcript levels on at least 2 occasions. Only 13 of these patients experienced CML progression. Of these 13, 11 patients had either lost an MMR or never achieved it and had a greater than 1-log increase in the BCR-ABL transcript level, suggesting that caution should be used when interpreting rising
BCR-ABL levels in patients with CCyR.

Early molecular response to second-generation TKIs can also predict survival and guide subsequent therapy. Branford et $\mathrm{al}^{43}$ and Milojkovic et al. ${ }^{44}$ showed that measuring BCR-ABL transcript levels at 3 months after the switch could predict response to second-generation TKIs, thus providing further information on the value of continuing treatment with these agents. 
A

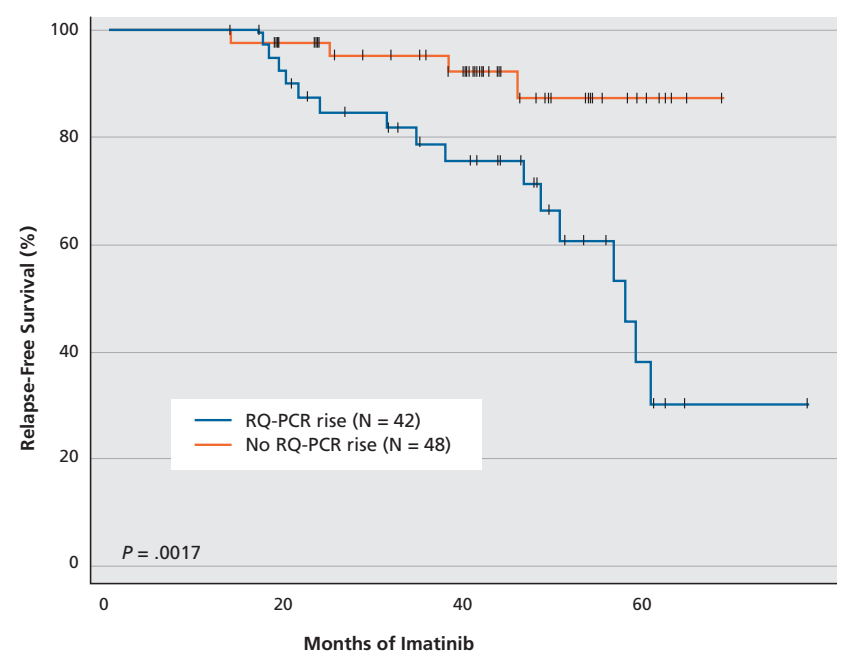

B

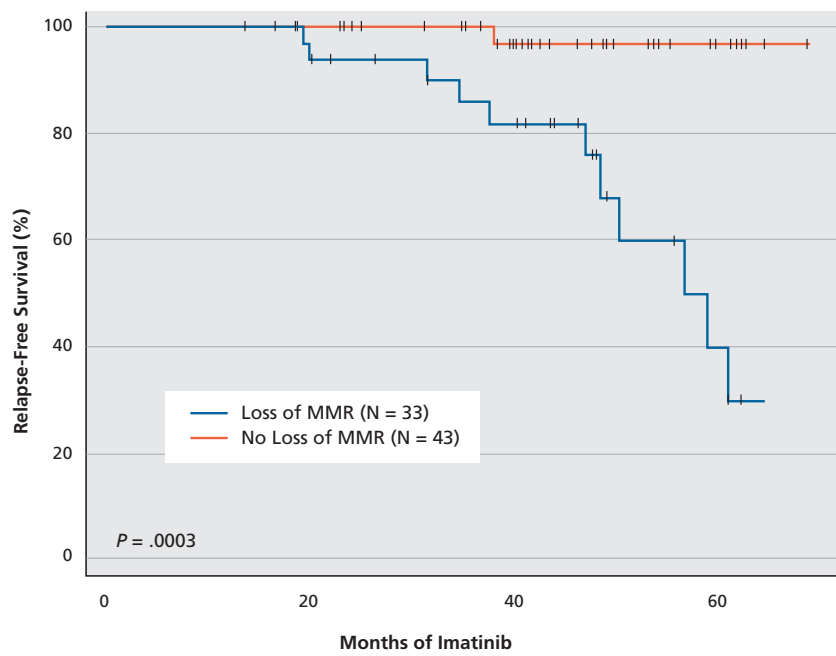

Figure 2 A half-log increase in BCR-ABL RNA levels predicts shorter relapse-free survival. A) Cumulative rate of relapse-free survival (Kaplan-Meier method) for subjects with increasing BCR-ABL RNA levels $(>0.5 \log ; \mathrm{n}=42)$ versus those with stable or declining BCR-ABL RNA ( $\mathrm{n}=48)$. From Press RD, Galderisi C, Yank R, et al. A half-log increase in BCR-ABL RNA predicts a higher risk of relapse in patients with chronic myeloid leukemia with an imatinib-induced complete cytogenetic response. Clin Cancer Res 2007;13:6140, with permission. B) Loss of major molecular response (MMR) predicts shorter relapse-free survival. Cumulative rate of relapse-free survival (Kaplan-Meier method) for the subset of patients $(\mathrm{n}=76)$ experiencing MMR, split into those with $(\mathrm{n}=33)$ and without ( $n=43$ ) subsequent loss of MMR (to < 2.5-log drop). From Press RD, Galderisi C, Yank R, et al. A half-log increase in BCRABL RNA predicts a higher risk of relapse in patients with chronic myeloid leukemia with an imatinib-induced complete cytogenetic response. Clin Cancer Res 2007;13:6141, with permission.

Several studies have examined the implications of monitoring BCR-ABL after hematopoietic stem cell transplantation (HSCT). Radich et al. ${ }^{45}$ reported that patients who had early PCR-positivity (6 or 12 months after HSCT) had a 42\% risk for experiencing disease relapse compared with only $3 \%$ in patients who tested PCR-negative.This study also showed that early PCR-positivity is associated with more aggressive disease and a high risk for relapse. The prognostic significance of monitoring BCR-ABL transcripts after allogeneic HSCT was also confirmed in subsequent trials. ${ }^{46,47}$ Thus, monitoring MRD after HSCT may help identify the subgroup of patients who may benefit from alternative treatment options.

Currently, no specific guidelines exist for changing therapy based on rising BCR-ABL transcripts detected with RT-PCR. However, close monitoring is essential for these patients. Changes of therapy based solely on a rising BCR-ABL level should occur only in the context of a clinical trial. Table 2 provides NCCN recommendations for monitoring MRD.

\section{Mechanisms of Resistance to Imatinib}

Primary hematologic resistance (failure to experience hematologic response within 3-6 months of initiation of treatment) is very rare in patients with newly diagnosed chronic phase CML. Primary cytogenetic resistance (failure to experience any level of cytogenetic response at 6 months, $\mathrm{MCyR}$ at 12 months, or CCyR at 18 months) is evident in $15 \%$ to $25 \%$ of patients. Secondary resistance is defined as the subsequent loss of response after initial response to imatinib. Mutations in BCR-ABL kinase domain are the main mechanism of resistance to imatinib in the chronic phase. Recent findings suggest that secondary resistance to imatinib is multifactorial, and several other mechanisms of resistance independent of BCR-ABL kinase domain mutations have been reported. ${ }^{48}$

Pharmacologic Mechanisms: Alpha-1-glycoprotein binds to imatinib, and excessive binding has been shown to alter its pharmacokinetics. ${ }^{49}$ Imatinib plasma levels have been shown to correlate with response to therapy in patients taking a standard dose of imatinib. ${ }^{50,51}$ In the IRIS study, maintaining an imatinib trough level at or higher than $1000 \mathrm{ng} / \mathrm{mL}$ was important for achieving CCyR. ${ }^{50}$ Early dose adjustments might improve clinical responses in patients with low plasma levels of imatinib. However, Ault et 
al. ${ }^{52}$ recently reported that plasma levels of imatinib had no correlation with response to therapy in patients on different dose schedules. The clinical value of monitoring plasma levels of imatinib remains to be clearly defined.

Aberrant expressions of drug transporters also contribute to resistance through altering the intracellular concentration of imatinib. ${ }^{53}$ Overexpression of the multidrug resistance gene MDR1 decreases the intracellular concentration of imatinib, leading to $B C R-A B L$ gene amplification, which confers resistance to imatinib. ${ }^{53}$ Higher activity of the human organic cation transporter-1 (OCT-1) is associated with excellent molecular response irrespective of dose, whereas response was highly dose-dependent in patients with low OCT-1 activity. ${ }^{54,55}$ However, cellular uptake of dasatinib or nilotinib seems to be independent of OCT-1 expression. ${ }^{56,57}$ Thus, patients with low-OCT-1 expression might have better outcomes with dasatinib or nilotinib.

The cytochrome P450 enzymes, CYP3A4 or CYP3A5, predominantly metabolize imatinib in the liver. Drugs that induce CYP3A4/5 enzyme levels are known to decrease the therapeutic concentrations of imatinib. ${ }^{58} \mathrm{CY} 3 \mathrm{~A} 4 / 5$-inducing drugs, such as anticonvul- sants and steroids, should be used with caution in patients receiving imatinib, and appropriate alternatives should be explored to maximize treatment outcome.

BCR-ABL Kinase Domain Mutations: The most common mechanism of resistance is the reactivation of BCR-ABL activity. This occurs most often through mutations in the ABL tyrosine kinase domain of BCR-ABL gene, and less frequently through $B C R-A B L$ gene amplification or increased $B C R-A B L$ gene expression ${ }^{59,60}$ In patients who achieved very low levels of BCR-ABL transcripts, those who subsequently experienced a more than 2 -fold increase in $B C R-A B L$ levels had a higher risk for emergence of BCR-ABL mutations than those with stable or decreasing BCR-ABL. ${ }^{61}$

Point mutations in the $A B L$ kinase domain are emerging as the most frequent mechanism of resistance. In a large study of 319 patients with chronic phase CML, Khorashad et al. ${ }^{62}$ found that kinase domain mutations were the only independent predictors of the loss of $\mathrm{CCy}$, and these patients had a higher risk for progression than those without a mutation. Some studies have linked mutations in the ATP phosphate-binding loop (P-loop) to poor prognosis and high risk for progression in patients

\section{Table 2 NCCN Recommendations for Monitoring Response and Mutational Analysis}

\begin{tabular}{|c|c|}
\hline Test & Indication \\
\hline \multirow[t]{3}{*}{ Cytogenetics } & $\begin{array}{l}\text { - } \mathrm{BM} \text { cytogenetics at diagnosis to establish disease stage. If collection of } \mathrm{BM} \text { is not feasible, FISH } \\
\text { on a PB specimen using dual probes for the } B C R \text { and } A B L \text { genes is an acceptable method for } \\
\text { confirming the diagnosis of } C M L\end{array}$ \\
\hline & $\begin{array}{l}\text { - At } 6,12 \text {, and } 18 \text { months from initiation of therapy to assess response to imatinib, until CCyR. } \\
\text { If CCyR is experienced at either of the earlier time points, then cytogenetics do not need to be } \\
\text { repeated }\end{array}$ \\
\hline & $\begin{array}{l}\text { - After CCyR, every } 12 \text { months to look for newly acquired cytogenetic changes (optional) or } \\
\text { anytime } B C R-A B L \text { increases }\end{array}$ \\
\hline \multirow[t]{3}{*}{$\begin{array}{l}\text { RT-PCR for } B C R-A B L \\
\text { transcript levels }\end{array}$} & $\begin{array}{l}\text { - At diagnosis to establish baseline } B C R-A B L \text { level and every 3-6 months after } C C y R \text { is reached } \\
\text { after imatinib therapy, to monitor major molecular response ( } \geq 3 \text {-log reduction) or increase in } \\
B C R-A B L\end{array}$ \\
\hline & $\begin{array}{l}\text { - If a rising level of } B C R-A B L \text { transcripts (1-log increase) with a major molecular response is } \\
\text { present, RT-PCR analysis should be repeated in } 1 \text { to } 3 \text { months; if no major molecular response } \\
\text { occurs, then BM cytogenetics is recommended }\end{array}$ \\
\hline & $\begin{array}{l}\text { - Quantitative RT-PCR monitoring (every } 3 \text { months for } 2 \text { years, then } 6 \text { months for } 3 \text { years) after } \\
\text { cytogenetic remission after allogeneic HSCT }\end{array}$ \\
\hline \multirow{2}{*}{$\begin{array}{l}\text { ABL tyrosine kinase } \\
\text { domain point } \\
\text { mutation analysis }\end{array}$} & - Before initiation of treatment for advanced-phase disease \\
\hline & $\begin{array}{l}\text { - If there is inadequate initial response (failure to experience CHR at } 3 \text { months, minimal } \\
\text { cytogenetic response at } 6 \text { months, or MCyR at } 12 \text { months), any sign of loss of response, or an } \\
\text { increase in } B C R-A B L \text { transcript levels }\end{array}$ \\
\hline
\end{tabular}

Abbreviations: $\mathrm{BM}$, bone marrow; CCyR, complete cytogenetic response; $\mathrm{CHR}$, complete hematologic response; $\mathrm{CML}$, chronic myelogenous leukemia; FISH, fluorescence in situ hybridization; HSCT, hematopoietic stem cell transplantation; MCyR, major cytogenetic response; PB, peripheral blood; RT-PCR; reverse transcription polymerase chain reaction. 
receiving imatinib, ${ }^{63-66}$ but other studies could not confirm this finding. ${ }^{67}$ However, dasatinib induced comparable $\mathrm{MCyR}$ rates in imatinib-resistant patients irrespective of the presence of P-loop or other mutations. ${ }^{17,68,69}$ Branford et al. ${ }^{66}$ observed that although patients with accelerated phase CML had a higher incidence of P-loop mutations, the difference in frequency of mutation was significant between early chronic and accelerated phase, compared with that between accelerated and late chronic phase.

The presence of T315I mutation confers the highest resistance to imatinib, dasatinib, and nilotinib. ${ }^{70,71}$ Jabbour et al. ${ }^{71}$ reported that survival of patients with T315I depends on disease stage. Unsurprisingly, survival is similarly poor among patients in accelerated and blast phase with or without the T315I mutation.

BCR-ABL-Independent Pathways of Resistance: Additional chromosomal abnormalities, a process known as clonal evolution, develop in approximately $80 \%$ of patients with CML. Clonal evolutions are considered a feature of advanced phase CML, and patients with clonal evolution are more likely to harbor BCR-ABL-independent mutations. In patients with chronic phase CML treated with imatinib, O'Dwyer et al. ${ }^{72}$ identified clonal evolution and failure to achieve MCyR by 6 months as adverse prognostic factors for relapse. Jabbour et al. ${ }^{67}$ also reported that development of clonal evolution is associated with worse survival; mutational status had no impact on survival. However, clonal evolution is associated with a better prognosis when considered the only criteria for disease progression compared with other accelerated features. ${ }^{73,74}$

Together, these data suggest that mutational analysis would be helpful in identifying subgroups of patients that demand careful monitoring, because these patients are at a higher risk for progression, and second-line TKIs are available for patients who become resistant to imatinib. Table 2 provides NCCN recommendations for mutational analysis.

CML Stem Cells: CML is one of the best examples of a "stem cell" malignancy, first described by Fialkow et al. ${ }^{75}$ more than 3 decades ago. More recently, increasing data have attempted to better define the clinical implications of CML stem cells in hopes of developing more selective treatments for these malignancies. ${ }^{76-79}$
CML stem cells seem to share many common characteristics with their normal hematopoiesismaintaining counterparts. These characteristics include the ability to undergo orderly differentiation and to self-renew. Moreover, the CML stem cell population is relatively small, is normally maintained in a quiescent state, and has relatively high expression of both aldehyde dehydrogenase (ALDH) and ATPbinding cassette transporters and low expression of OCT $-1 .{ }^{80}$ Altogether, these characteristics contribute to cytotoxic drug resistance, which traditionally targets rapidly cycling cells, and resistance to TKIs whose reduced intracellular concentrations might limit their full impact. This important population of cells is clearly distinctive from the bulk of the tumor and helps explain the clinical responses to imatinib. Imatinib is able to quickly stabilize and eliminate most of the tumor in patients with newly diagnosed chronic phase CML, yet is unable to render patients completely free of disease because most still have measurable disease even after many years of treatment.

Interestingly, the clinical responses observed in patients treated with interferon are different. Formerly standard care for medically managing patients with CML, interferon commonly resulted in hematologic stabilization and a gradual reduction in $\mathrm{Ph}+$ hematopoiesis over months to years. Unfortunately, complete cytogenetic and molecular remissions were relatively rare. Nevertheless, when these responses were seen and sustained, not only was discontinuing interferon possible, but many patients remained without recurrence many years off therapy. The dynamics of these responses suggest that in patients with CML, both the bulk of the tumor and the early progenitor population may be differentially sensitive to imatinib versus interferon. This may explain the difference in clinical outcomes between these agents.

Available evidence supports the clinical observations noted earlier: imatinib is effective against differentiated progenitors, but primitive CML stem cells seem resistant to it. ${ }^{81-83}$ At significant concentrations, imatinib seems to suppress the proliferation of primitive stem cells but does not eradicate residual CML stem cells completely. ${ }^{82}$ Furthermore, a differential sensitivity to the effects of imatinib appears to exist within the stem cell compartment, with the inhibitory effect of imatinib in vitro being much more pronounced against the mature CD34+CD38+lin- 
stem cells than the primitive CD34+CD38-lin-stem cells. ${ }^{77}$ Angstreich et al. ${ }^{84}$ showed that imatinib was more active against differentiated CML progenitors and that interferon was more active against the primitive CML progenitors, ${ }^{84}$ and raised the question of whether concurrent or sequential use of these agents might optimize the activity of these 2 drugs against their respective targets. The toxic side effects associated with long-term use of interferon are of concern.

The fact that the primitive CML stem cell population has a distinct phenotype (CD34+, CD38-, lin-) compared with the more differentiated progeny (CD34+, CD38-, lin+) may provide unique targets for novel therapies. However, this approach is also likely to have challenges that are not necessarily intuitive. As an example, the importance of the BCR$A B L$ gene rearrangement, which defines the biology of CML, may have little impact on the functionality of primitive CML stem cells. Data suggest that this CML-defining signal may be either minimally expressed or absent in primitive CML stem cells. Trials performed more than a decade ago showed that primitive progenitors with $B C R-A B L$ rearrangement do not express the fusion protein (P210) and BCRABL mRNA. ${ }^{85}$ However, this difference is not distinguished by real-time quantitative PCR assay (using K562 CML cell line as the standard), which showed that BCR-ABL expression was relatively equal between different types of CD34+ progenitors. This finding suggests that BCR-ABL is likely not the best marker for distinguishing or targeting the population of primitive CML cells.

Many new markers have now been identified in early CML progenitors, and these may offer better opportunities to identify and study the primitive stem cell population. ${ }^{86}$ The clinical implications of 2 examples, proteinase 3 (PR3) and preferentially expressed antigen of melanoma (PRAME), are briefly touched on in the following sections.

PR3: One gene that has generated a great deal of interest in CML is the PR3 differentiation gene. High expression of PR3 at diagnosis, along with low expression of CD7 and high expression of neutrophil elastase (ELA2), has been identified as a potentially important predictor of longer survival in patients with chronic phase CML. ${ }^{87}$ In patients with advanced phase CML, higher expression of PR3 and ELA2 in CD34+ progenitors before HSCT is associated with lower incidences of relapse-related death, improved disease-free survival, and overall survival. ${ }^{88}$ Radich et al. ${ }^{10}$ also reported that decreased expression of ELA2 was associated with disease progression. The fact that PR3 is expressed at higher levels in the more differentiated progenitors compared with early ones may explain the inconsistent clinical findings. PRAME: Overexpressed in various solid tumors, PRAME is a good prognostic marker of clinical outcome and is generally not found in normal tissues. ${ }^{89}$ Recent reports have shown that PRAME is overexpressed in acute and chronic leukemias. ${ }^{90-92}$ CD34+ cells in advanced phase CML had a higher PRAME expression than those in chronic phase. ${ }^{92}$ In an extensive GEP study of patients with CML, Radich et al. ${ }^{10}$ showed that up-regulation of PRAME is one of the significant prognostic factors associated with disease progression. PRAME was expressed in almost all of the patients in blast crisis and only at very low levels in $50 \%$ of patients in chronic phase. A trend was also seen toward increased expression in patients with poor response to imatinib, suggesting that PRAME expression in patients newly diagnosed with chronic phase CML is an indicator of poor treatment response. ${ }^{93}$

Together, PR3 and PRAME help illuminate the molecular underpinnings of CML and may offer some rationale for developing targeted agents beyond imatinib. Although no one pathway seems sufficient, combination strategies effectively targeting pathways active in the early stem cell progenitors may begin to indicate an eventual cure for CML.

\section{Conclusions}

Imatinib and other TKIs targeting BCR-ABL are very effective in treating the bulk of the tumor mass and produce dramatic clinical responses. However, the FDA-approved TKIs do not seem to completely eradicate all CML cells.

Targeting the residual tumor population may hold promise in improving the responses seen with imatinib alone. However, the development of these therapies has been limited partly by biologic properties that this residual population of cells share with normal hematopoietic stem cells.

New findings revealing molecular characteristics of the CML stem cell population continue to contribute to the understanding of cancer biology and may provide targets for new drugs and approaches to improve clinical outcomes.

Ideally, cancer stem cell-targeted therapies should be used in patients when they achieve MRD. 
CML may be an ideal cancer to focus on the impact of imatinib on achieving MRD in most patients. Integrating the concept of CML stem cells into drug development and clinical trial designs may have the potential to completely "cure" patients with CML.

\section{Molecular Markers in Acute Leukemias}

\section{Acute Myeloid Leukemia}

Acute myeloid leukemia (AML) is associated with variable clinical outcomes, and therefore molecular markers could help stratify patients ${ }^{94}$ and predict relapse. However, none of these molecular markers has reached the same level of agreement as BCR-ABL in CML. This report concentrates on the role of the molecular markers in detecting MRD, and hence predicting relapse. Molecular markers in AML can be grouped into 3 categories: fusion genes, gene mutations, and aberrantly expressed genes. The clinical implications of some of the most common markers from each group are discussed briefly.

Fusion Genes: PML-RAR $\alpha$ (promyelocytic leukemia gene/retinoic acid receptor alpha), CBF $\beta-M Y H 11$ (core binding-factor beta gene/myosin heavy chain 11 gene), AML1 (acute myeloid leukemia 1)-ETO, and MLL (mixed-lineage leukemia gene) are the 4 most common fusion gene transcripts that have been used as targets for detecting MRD using PCR-based assays and to predict clinical outcome after chemotherapy or transplantation in patients with AML.

PML-RAR $\alpha$ : The translocation between chromosomes 15 and 17 fuses the RAR $\alpha$ gene on chromosome 17 with the PML gene on chromosome 15, resulting in the fusion transcript PML-RAR $\alpha$. This transcript is found in almost all patients with acute promyelocytic leukemia (APL) and its presence after remission is predictive of relapse.

CBF $\beta-M Y H 11$ : The fusion transcript CBF $\beta-M Y H 11$ is a fusion of the CBF $\beta$ gene at chromosome $16 \mathrm{q} 22$ with the MYH11 gene at chromosome $16 \mathrm{p} 13$ presenting as $\operatorname{inv}(16) / t(16 ; 16)$. Amplification of this fusion transcript using qualitative RT-PCR in bone marrow and peripheral blood has been used to detect MRD and assess the risk for relapse in patients with $\operatorname{inv}(16) / t(16 ; 16)$. However, use of the qualitative assay resulted in conflicting results, ${ }^{95}$ suggesting that quantitative RT-PCR may be a more useful tool.

AML1-ETO: The AML1-ETO fusion transcript results from the $t(8 ; 21)$, which fuses the AML1 (also
RUNX1) gene on chromosome 21 with the 8 to 21 (ETO) gene on chromosome 8. This fusion transcript can be detected with nested RT-PCR in most patients experiencing long-term remission after conventional chemotherapy or autologous or allogeneic HSCT. ${ }^{96}$ The discrepancy between clinical cure and the presence of MRD found with nested RT-PCR suggests that this qualitative assay was too sensitive. MLL: The MLL gene on chromosome 11q23 is involved in approximately $10 \%$ of AML and associated with adverse outcome. ${ }^{97} \mathrm{MLL}$ can be aberrantly expressed, either from partial tandem duplication or partnering with more than 50 different fusion genes. A subset of patients with aberrant MLL may experience long-term remission after conventional chemotherapy. Thus, monitoring MRD would be of great value during follow up of these patients.

Prognostic Significance of Fusion Genes: The predictive value of postconsolidation quantitative PCR in patients with APL has been shown in several prospective trials. ${ }^{98}$ The technique has to be able to detect a PML-RAR $\alpha$-positive cell among 103 to 104 normal cells. However, physicians should refrain from basing clinical decisions on earlier postinduction, molecular results because these did not correlate with outcome.

Molecular remission has become the therapeutic objective in APL and is used as a surrogate marker for survival. Furthermore, molecular monitoring is also used after completion of treatment because molecular relapse precedes morphologic relapse. However, the frequency of monitoring is still not established. Some groups tend to use the pretreatment clinical characteristics to guide the timetable for molecular monitoring (e.g., more frequent monitoring for patients with hyperleukocytosis at presentation).

Higher copy numbers of CBF $\beta-M Y H 11$ assessed using RT-PCR at diagnosis had a significant correlation with high percentage of bone marrow involvement, and appeared to correlate with shorter response duration in 1 group but not in others. ${ }^{99,100}$ Furthermore, patients experiencing complete remission after chemotherapy with 10 or more copy numbers of CBF $3-M Y H 11$ had a significantly shorter response duration and higher risk for disease relapse. ${ }^{99}$ In others, a log rise in transcript level at any stage relative to the remission level was used to predict relapse. ${ }^{100,101}$ The recent finding of $c$-Kit mutations, especially those affecting exon 17 , as a predictor for higher re- 
lapse risk and shorter survival may explain the early relapse in some patients. ${ }^{102,103}$ No studies have yet analyzed the role of MRD measurement in patients with inv(16)/t $(16 ; 16)$ without $c-$ Kit mutation.

Marcucci et al. ${ }^{104}$ showed the feasibility of RT-PCR for the quantitative detection of AML1-ETO fusion transcript in patients with $\mathrm{t}(8 ; 21)$-associated AML at diagnosis and after high-dose cytarabine and anthracycline-based therapy. ${ }^{104}$ All of the 5 patients who had at least 1000 copies of AML1-ETO fusion transcript at diagnosis showed a 2- to 4-log reduction in the transcript levels after induction chemotherapy; 1 patient, who had high transcript levels after remission induction chemotherapy, eventually experienced disease relapse. Similar to the studies in inv(16)/t(16;16), a log rise in AML1-ETO transcript level at any stage relative to the remission level heralded relapse. ${ }^{100,101}$ These studies confirm the role of quantitative RT-PCR in defining relapse risk. However, the recent finding that c-Kit mutations have a negative impact on outcome in $\mathrm{t}(8 ; 21)$ AML may explain the early relapse experienced by some of the patients. ${ }^{102,103}$

Several groups described monitoring MRD in patients with AML with MLL aberrations. ${ }^{105-108}$ The use of real-time PCR to quantify MLL partial tandem duplication revealed that at least a $2-\log$ reduction 2 months and beyond after the start of therapy was associated with a longer survival, suggesting that measuring MRD in this patient population can be used prognostically. ${ }^{105}$ However, molecular relapse preceded clinical relapse by only 35 days. Similarly, for MLL-AF9 resulting from $\mathrm{t}(9 ; 11)(\mathrm{p} 22 ; \mathrm{q} 23)$, patients with negative quantitative PCR test results had lower cumulative incidence of relapse and better overall survival than those with at least 1 positive measure. ${ }^{108}$ As in patients with MLL and partial tandem duplication, the interval between molecular and clinical relapse was short (4-6 weeks). Therefore, these patients would have to be monitored very closely.

Gene Mutations: Mutations of FMS-like tyrosine kinase 3 (FLT3) receptor are detected in approximately $30 \%$ of patients with AML. ${ }^{109}$ The presence of this mutation, either in the form of internal tandem duplication (ITD) or a point mutation in the activation loop, is associated with a high risk for relapse in patients with normal karyotype, whereas the mutation does not affect the complete response rate. $^{110}$ In patients with normal karyotype AML, the presence of FLT3 receptor mutation correlates with higher risk for relapse compared with FLT3negative disease.

FLT3 was used to detect MRD, concentrating on patients with normal karyotype AML for whom no other marker is available. ${ }^{111}$ However, not all patients who present with FLT3 ITD/point mutation maintain this aberration at relapse, suggesting that FLT3 aberrations are unstable. ${ }^{112-114}$ Therefore, using FLT3 in following up patients for MRD and predicting relapse may be misleading.

Insertion mutations in exon 12 of the nucleophosmin (NPM1) gene is a characteristic feature of a large group of patients with AML with normal karyotype. ${ }^{94}$ Its main role in predicting better outcome is reserved for patients with normal karyotype AML whose cells do not carry FLT3 aberrations. ${ }^{115,116}$ Several groups explored the validity and prognostic significance of MRD detection using quantitative PCR in patients with NPM1. ${ }^{117,118}$ After patients experienced complete remission, the presence of detectable mutations predicted relapse if no further chemotherapy was given. Furthermore, failure to achieve a $2-\log$ reduction after consolidation therapy predicted shorter overall and relapse-free survival. ${ }^{119}$ Interestingly, NPM1 mutations are more stable than FLT3 aberrations, and therefore are more suitable for monitoring MRD. ${ }^{119}$

Aberrant Gene Expressions: For patients with no specific marker, the Wilms' tumor 1 (WT1) gene, located on chromosome 11p13, has been suggested as a marker for MRD because it is detected in $75 \%$ to $100 \%$ of patients with AML. ${ }^{120}$ WT1 gene transcripts have been reported to be useful molecular targets for MRD detection using RT-PCR-based assays by some experts, but not others. ${ }^{121-129}$ In one study, patients with fewer than 1000 copies of WT1 after induction and second consolidation chemotherapy had significantly better disease-free and overall survival. $^{123}$ Interestingly, when comparing WT1 and NPM1 during follow-up in patients with AML, WT1 decreased rapidly after induction but maintained residual levels after treatment in patients experiencing complete remission, whereas NPM1 showed mild reduction after induction but was undetectable in long-term survivors. ${ }^{130}$

\section{Acute Lymphoblastic Leukemia}

The $\mathrm{Ph}$ chromosome resulting from $\mathrm{t}(9 ; 22)$ is detectable in approximately $20 \%$ to $30 \%$ of adult patients with acute lymphoblastic leukemia (ALL), with the 
incidence rising to more than $50 \%$ in patients aged 50 years or older, and is associated with adverse prognosis. ${ }^{131}$ Both fusion proteins of the BCR-ABL gene (p210 and p190) are equally expressed in adult patients with $\mathrm{Ph}+\mathrm{ALL}$, and the presence of p190 may help distinguish between CML in lymphoid blast crisis and $\mathrm{Ph}+\mathrm{ALL}$.

The most common method to detect MRD in ALL relies on the clonal rearrangement of the immunoglobulin (IG) and TCR genes, whose junctional regions are unique to the leukemic clone. ${ }^{132}$ Thus, the presence of rearranged genes is typically screened using PCR primers matched to the opposite sides of the junctions, to the $\mathrm{V}$ and $\mathrm{J}$ regions of various IG and TCR genes. Once an apparently clonal rearrangement is detected, the PCR products are then used for direct sequencing of the junctional regions of the IG/TCR gene rearrangements, which is then used to design junctional region-specific, or allele-specific, oligonucleotides. ${ }^{132}$

Most (> 95\%) B-lineage ALL (B-ALL) cases have IG gene rearrangements. ${ }^{133,134}$ Interestingly, cross-lineage TCR gene rearrangements also occur in up to $90 \%$ of B-ALL cases. ${ }^{135}$ TCR genes are rearranged in most cases of T-lineage ALL (T-ALL). ${ }^{136}$ Cross-lineage $I G$ gene rearrangements occur in approximately 20\% of T-ALL. ${ }^{133}$ Despite these caveats, monitoring MRD with PCR using either IG or TCR gene rearrangements is feasible and commonly used. As with fusion transcripts in AML, the most frequently used technique is real-time quantitative PCR. ${ }^{137}$

In adult ALL, one group showed that $23 \%$ of B-ALL lacked a clonal marker for PCR analysis. ${ }^{138}$ Another group showed that 10\% lacked this marker, ${ }^{139}$ with $7 \%$ having none detected and 3\% having clonal markers that were not suitable for MRD quantification. These results show that it's feasible to detect MRD through IG/TCR gene rearrangements in adult ALL.

The BCR-ABL fusion gene transcript has been used as a specific target for detecting MRD in adult patients with Ph+ ALL. ${ }^{140,141}$ Detection of BCR-ABL transcripts after chemotherapy or transplantation is associated with a high risk for relapse. ${ }^{142}$ Stirewalt et al. ${ }^{143}$ identified MRD detection and p190 transcript expression posttransplant as risk factors for relapse. In a more recent study, rapid molecular response after chemotherapy in combination with imatinib was not associated with more favorable prognosis in pa- tients with Ph+ ALL. ${ }^{144}$ Secondly, although a single observation of elevated MRD predicted relapse, allogeneic HSCT seemed to be able to overcome that adverse effect.

Ikaros zinc finger transcription factor (IKZF1) plays an important role in differentiation and proliferation of all lymphoid lineages ( $\mathrm{T}$ - and B-cell). Deletions of IKZF1 gene are found in Ph+ ALL and lymphoid blast crisis but not in myeloid blast crisis or chronic phase CML. ${ }^{145}$ Recently, Paulsson et al. ${ }^{146}$ reported that the IKZF1 gene was deleted in $27 \%$ of adult patients, compared with only $9 \%$ of childhood cases. The deletions are associated with resistance to TKIs, worse clinical outcomes, and higher relapse rates. Mullighan et al. ${ }^{147}$ also reported that the deletion of IKZF1 is found in $83.7 \%$ of patients with BCR-ABL-positive ALL. The deletions are acquired as CML transforms from chronic phase to lymphoid blast crisis.

IKZF1 gene, located on chromosome 7p12, can give rise to isoforms with and without DNA binding properties. All isoforms have $2 \mathrm{C}$-terminal zinc finger motifs but differ in the number of $\mathrm{N}$-terminal motifs, which dictates the sequence specificity and DNA affinity. ${ }^{148}$ Ikaros proteins with fewer than $3 \mathrm{~N}$ terminal zinc finger motifs cannot bind to DNA, and play a dominant negative role in the transcription. IK6 is a dominant negative isoform because it lacks all of the $4 \mathrm{~N}$-terminal zinc finger motifs. In patients with $\mathrm{Ph}+\mathrm{ALL}$ treated with dasatinib and imatinib, IK6 isoform was dominant in 49\%. ${ }^{149}$ The expression of IK6 also correlated with the BCR-ABL transcript levels, and overexpression was associated with resistance to both dasatinib and imatinib. IKZF1 expression provides insight into the evolution of the disease and might be valuable in identifying patients destined to progress from chronic phase to lymphoid blast crisis.

\section{Conclusions}

Advances in the understanding of the molecular biology of leukemia have lead to dramatic changes in monitoring and treatment. In CML, molecular monitoring has now become a fundamental method in defining patient response and detecting resistance. Molecular markers of progression will probably be available soon, and inroads to understanding the biology of progression will spawn innovative treatments for advanced phase CML. In acute leukemia, the past few years have seen the development of many new markers that are relevant in prognostica- 
tion, and potentially in monitoring and treatment. Like CML, treatment algorithms in acute leukemia probably will be defined by the distinct molecular biology of the individual disease.

\section{Molecular Markers in Non-Hodgkin's Lymphoma}

The management of patients with non-Hodgkin's lymphoma (NHL) continues to pose challenges because of its clinical, pathologic, and molecular heterogeneity. Clinical prognostic indices, such as the International Prognostic Index (IPI), Follicular Lymphoma International Prognostic Index (FLIPI), and the recently reported Mantle Cell Lymphoma International Prognostic Index (MIPI), are powerful tools for establishing prognosis at diagnosis. ${ }^{150-152}$ The clinical prognostic indices are based on easily obtained patient characteristics, such as age, performance status, stage of disease, serum lactate dehydrogenase (LDH) levels, and the number of extra nodal sites involved. Clinically based prognostic indicators remain the powerful prognostic tools available; however, considerable variability in outcomes remains within each risk category. Molecular markers provide additional prognostic information that can further augment the usefulness of clinically based risk stratification.

\section{Methods of Detection of Molecular Markers}

Immunophenotypic Analysis: Immunophenotypic analysis (IPA) can be performed using either immunohistochemistry or flow cytometry. Both methods rely on the availability of antibodies that can identify the protein of interest. The choice between immunohistochemistry and flow cytometry depends mainly on the expertise, type of tissues received, and resources available to the hematopathologist. In some cases, flow cytometry and immunohistochemistry are complementary diagnostic tools. ${ }^{153}$

IPA is the most widely used method for detecting molecular markers that are proteins in lymphoid malignancies. The major advantage of immunohistochemistry is its capacity to analyze formalin fixed paraffin-embedded (FFPE) tissues and simultaneously provide morphologic analysis. However, variability in tumor preservation, fixation techniques, detection systems, and assay interpretation may result in discordant observations. Standardization of tissue processing and immunohistochemical assay is essential to ensure the reproducibility of results and concordance in the findings from different laboratories. ${ }^{154}$ The Lunenberg Lymphoma Biomarker Consortium (LLBC) has shown that semiquantitative immunohistochemistry is feasible and reproducible, but that the rates of concordance between laboratories depend on the particular biomarker. ${ }^{154}$

Flow cytometry immunophenotyping (FCI) is also used to identify the expression of prognostic markers in NHL subtypes, in addition to its wellestablished use in diagnosing lymphomas. ${ }^{155,156}$ Flow cytometry can be performed on peripheral blood, bone marrow aspirates, fresh tissue biopsies, and all types of body fluids. The advantages of flow cytometry include its ability to simultaneously examine multiple parameters of single cells; analyze antigen with antibodies that cannot be used on FFPE tissue; provide quantitative analysis of the expression level; and work with small samples. Flow cytometry is very valuable for determining clonality in primary diagnosis and in staging studies. ${ }^{157}$ The major disadvantage of flow cytometry is its requirement of fresh, unfixed tissue samples for analysis and the lack of morphologic information.

Cytogenetic Analysis: CGA and FISH are used in certain circumstances to identify the specific chromosomal translocations and copy number alterations that are used as prognostic markers in particular NHL subtypes. ${ }^{158}$ CGA has to be performed on cultures of viable cells. In some cases CGA is uninformative because of low mitotic indices and poor chromosome morphology.

FISH is used as an alternative method to identify chromosomal abnormalities that are not detectable by CGA or when CGA is not performed. ${ }^{159,160} \mathrm{FISH}$ can be performed on peripheral blood specimens, bone marrow aspirates, or fixed or sectioned tissue samples. Unlike CGA, FISH can be performed both on interphase and metaphase cells. Interphase FISH is particularly useful when metaphase cytogenetics may be difficult in the largely quiescent cells of some lymphoid malignancies, and has been used to detect $\mathrm{t}(14 ; 18)$ translocation, BCL6 gene rearrangements, and many other abnormalities. ${ }^{161,162}$ The major limitations of FISH include its inability to detect more than a few genetic abnormalities simultaneously. The advent of newer methods, such as multicolor FISH and spectral karyotyping, allow simultaneous visualization of the entire karyotype. ${ }^{158}$ 
Comparative genomic hybridization (CGH) is an alternative technique used to detect genomic imbalances. ${ }^{163}$ The unique advantage of $\mathrm{CGH}$ is its capacity to screen the entire genome for DNA copy number changes without using living cells. Array$\mathrm{CGH}$ is performed on arrayed sequences of genomic DNA instead of metaphase chromosomes. Currently, DNA arrays for CGH can be constructed with very high-density coverage of the genome, resulting in a very high resolution platform for genome-wide detection of chromosomal abnormalities. ${ }^{7,164}$

PCR: PCR assays have been used to detect some of the common genetic abnormalities associated with lymphoid malignancies and to quantitate target gene expression for the development of gene expressionbased prognostic models. Molecular diagnostic analyses can be performed on a small amount of tissue and on archival paraffin-embedded material.

In some instances, it is preferable to perform PCR on complementary DNA (cDNA) rather than genomic DNA, a procedure called RT-PCR. In RTPCR, mRNA is first transcribed to cDNA, which is used as a template for subsequent PCR amplifications. Quantitative RT-PCR is a sensitive method for detecting mRNA levels. PCR assays can be used to identify translocations that are strongly associated with certain lymphomas when the breakpoints are sufficiently clustered, such as the major and minor break point cluster regions involved in the $t(14 ; 18)$ translocation. ${ }^{3,165,166}$ However, PCR analysis is not suitable for detecting BCL6 gene rearrangements because of the involvement of a large number of translocation partners. RT-PCR is often applied in the setting of novel fusion genes, such as the NPM-ALK seen in anaplastic large cell lymphoma. In these cases, normal RNA processing excises introns and enables the use of primers for the coding regions of the 2 partner genes.

In real-time PCR, the amplified DNA is quantified as it accumulates in the reaction after each amplification cycle. ${ }^{167}$ This methodology allows the combination of DNA amplification and product detection into 1 homogenous assay thus eliminating the need for post-PCR processing. Real-time PCR is the method of choice for performing quantitative PCR. The major advantage of this assay is its high sensitivity and accuracy and wide dynamic range for quantifying DNA and transcript levels and fast turnaround time.
GEP: GEP is a powerful tool to identify multiple molecular markers simultaneously in malignant lymphomas. ${ }^{168}$ GEP is usually performed with a microarray using RNA isolated from tissues, labeled with a detectable marker, and allowed to hybridize to gene-specific probes on the array. The fluorescence intensity on each gene-specific probe corresponds to the level of expression of the corresponding transcript. Supervised and unsupervised methods are used for data analysis. Quantitative real-time RTPCR is considered a standard assay for validating microarray data.

The Microarray Gene Expression Data Society developed standards for data reporting, known as minimal information about a microarray experiment (MIAME). ${ }^{169}$ Concern has been expressed about the reliability and reproducibility of GEP experiments and the feasibility of cross-platform comparison of results. With improvement of microarray technology, studies that are carefully performed under strictly controlled conditions are highly reproducible using the same array platform. ${ }^{170,171}$ Cross-platform comparison is more difficult; however, recent large multicenter studies have found that the results are reasonably comparable even across different platforms. ${ }^{170,171}$ It is now recognized that although the measurement of individual genes may have substantial variations, the comparison of groups of genes is much more robust. ${ }^{172}$ These gene groupings are referred to as gene expression signatures and represent coordinated gene expression involved in specific biologic processes, such as proliferation or signaling. Therefore, properly and carefully performed microarray studies represent a useful approach for GEP.

Gene signatures identified by GEP may include the following groups:

- Signatures dividing tumors into biologic subgroups (e.g., subgroups of DLBCL) based on cell of origin (germinal center-derived vs. activated B-cell-derived) or based on certain functional characteristics, such as high level of BCR activation or oxidative phosphorylation.

- Signatures representing certain biologic functions of the tumor, such as proliferation or NF$\kappa \mathrm{B}$ activation.

- Signatures with relevance to host/tumor interaction, such angiogenesis, expression of major histocompatibility complex (MHC) molecules, or stromal cell composition. 
- Signatures predictive of response to therapy and outcome.

Although GEP looks promising, it is not yet ready for widespread clinical use because the methodology has not been standardized, findings require further validation, and optimal platforms have not been determined.

\section{DLBCL}

DLBCL is the most common aggressive subtype of NHL worldwide. The relative incidence has substantial geographic variation; for example, DLBCL accounts for approximately $30 \%$ of cases of NHL in the United States and Europe, but $46 \%$ of cases in Hong Kong and 59\% in the United Arab Emirates. DL$\mathrm{BCL}$ is characterized by various genetic abnormalities. Recurring chromosomal translocations occur in $50 \%$ of cases. The identification of specific chromosomal translocations and the corresponding protein expression has led to many novel molecular markers that have the capacity to predict outcome in patients with DLBCL. ${ }^{173,174}$

GEP: GEP has been used to identify 3 biologically and clinically distinct subtypes of DLBCL: germinal center B-cell (GCB) subtype, activated B-cell (ABC) subtype, and primary mediastinal DLBCL. ${ }^{175-177}$ The gene expression signature of the GCB subtype is characteristic of that of GCBs. In contrast, the gene expression signature associated with the $\mathrm{ABC}$ subtype is characterized by overexpression of a set of genes overexpressed in mitogen-activated B cells. ${ }^{176}$

Patients with GCB subtype have a significantly better overall survival after chemotherapy than those with $A B C$ subtype. The 5-year survival rate differed significantly between the GCB and ABC subtypes (62\% vs. $26 \%$, respectively) after $\mathrm{CHOP}$ (cyclophosphamide, doxorubicin, vincristine, prednisone)-like chemotherapy, ${ }^{176}$ a finding similar to that in an earlier report by Alizadeh et al. ${ }^{175}$ Even among patients who were at low risk according to IPI, those with the ABC subtype had a distinctly worse survival than those with the GCB subtype. Moreover, ABC cell lines and primary ABC-DLBCL samples also showed increased activity of the NF- $\mathrm{KB}$ signaling pathway, which could potentially block the apoptosis induced by chemotherapy and thus account for poor survival.

In addition to the $G C B$ versus $A B C$ distinction, Rosenwald et al. ${ }^{178}$ identified 3 additional gene expression signatures, which included the MHC class II gene-expression signature, the proliferation signa- ture, and the lymph node signature. High expression of lymph node signature is associated with improved survival in patients treated with $\mathrm{CHOP}$ or $\mathrm{CHOP}$ like chemotherapy. The loss of MHC class II gene and protein expression and high expression of the proliferation signature have been shown to be predictive of poor survival in patients with DLBCL. ${ }^{179}$

Lenz et al. ${ }^{180,181}$ recently re-examined the prognostic model in patients treated with CHOP-like chemotherapy combined with rituximab and reported a predictive model created from 3 gene-expression signatures (GCB, stromal-1, and stromal-2). In this analysis, patients with the GCB subtype still showed better survival than those with the ABC. High expression of stromal-1 signature was associated with favorable outcome and reflected extracellular matrix deposition and infiltration by histiocytic innate immune cells. In contrast, the stromal-2 signature was indicative of unfavorable prognosis and reflected angiogenesis and tumor blood vessel density. These results must be confirmed in another dataset or prospective trial. CALGB is conducting a prospective assessment of GEP in DLBCL in conjunction with a trial comparing R-CHOP with dose-adjusted EPOCH-R (etoposide, prednisone, vincristine, cyclophosphamide, doxorubicin, rituximab).

Several investigators have used the information generated by GEP studies to develop prediction models based on more commonly used techniques, such as immunohistochemistry and PCR-based methods. ${ }^{182-185}$

Hans et al. ${ }^{182}$ used immunohistochemistry to identify the 2 subtypes of DLBCL. GCB subtype was identified by either of the following immunophenotypes: 1) CD10-positive, BCL6 and MUM1negative; or 2) CD10-negative, BCL6-positive, and MUM1-negative. The lack of both CD10 and BCL6 or MUM1 positivity indicated a non-GCB subtype, which in turn was associated with poor overall survival. The 5 -year overall survival data (76\% for the GCB group vs. $34 \%$ for the non-GCB group) were similar to those reported using GEP. Although the combined analysis of CD10, BCL6, and MUM1, according to the algorithm, may be a surrogate for the GEP classification of GCB and ABC subtypes, there is a misclassification rate of $14 \%$. In an attempt to improve the accuracy of the Hans algorithm, Choi et al. ${ }^{186}$ added 2 new antibodies that help distinguish between the ABC and GCB subtypes. The impact of 
BCL6 in this algorithm is reduced and the misclassification rate has improved to $7 \%$ versus $14 \%$ for Hans's algorithm.

Lossos et al. ${ }^{183}$ created a 6 -gene predictive model using the real-time RT-PCR platform. ${ }^{183}$ The expression of FN1 along with LMO2 and BCL6 (both of which are highly expressed in the GCB subtype) correlated with prolonged survival. The other 3 genes (BCL2, CCND2, and SCYA3) are often highly expressed in the $\mathrm{ABC}$ subtype, and their high expression is associated with poorer outcome.

Studies based on immunohistochemistry have produced conflicting results, with the study by $\mathrm{Fu}$ et al. ${ }^{187}$ reporting that the addition of rituximab to CHOP-like chemotherapy improved overall survival for both GCB and ABC subtypes, but the GCB subtype still had a more favorable 3-year overall survival rate than the $\mathrm{ABC}$ subtype ( $85 \%$ vs. $69 \%$, respectively). In contrast, Nyman et al. ${ }^{188}$ showed that GCB subtype defined by immunohistochemistry had a significantly better survival rates than the nonGCB subtype in patients treated with chemotherapy, whereas the GCB subtype lost its prognostic significance with the addition of rituximab to chemotherapy. A recent GEP study of 233 cases by Lenz et al. ${ }^{189}$ indicates that the GCB subgroup continues to have better survival than the ABC subgroup, even with the addition of rituximab ( $86 \%$ vs. $68 \%$, respectively).

Single Prognostic Markers: Many single markers have been proposed as prognostic indicators, with some useful for distinguishing between the GCB and ABC subtypes. ${ }^{173}$ For example, GCET2(HGAL) and LMO2 are very strongly associated with the GCB subtype, whereas FOXP1, when it is highly expressed is a good marker for the ABC subtype. Similarly, a high level of expression of BCL2 helps identify cases with the ABC signature. PKC-beta and cyclin D2 also indicate an ABC derivation. BCL2, BCL6, and TP53 genes and their protein expression are probably the most intensively studied markers.

BCL2: BCL2 is an antiapoptotic protein that is upregulated by the $\mathrm{t}(14 ; 18)$ translocation, which juxtaposes the BCL2 gene on chromosome 18 with the $\operatorname{IgH}$ locus on chromosome 14 . BCL2 protein is expressed in approximately $40 \%$ to $60 \%$ of patients with DLBCL. The BCL2 gene rearrangement with $\mathrm{t}(14 ; 18)$ has been detected in approximately $20 \%$ of patients with DLBCL. This translocation occurs in approximately one third of patients with GCB-DLBCL, but not in those with ABC. ${ }^{190,191}$ This translocation also correlates with the expression of BCL2 protein and mRNA in the GCB subtype. However, BCL2 is also highly expressed in the $\mathrm{ABC}$ subtype in the absence of the $t(14 ; 18)$ translocation, indicating that the mechanism of BCL2 upregulation in this subtype is independent of $\mathrm{t}(14 ; 18)$.

High BCL2 expression was shown to be more frequent in patients with stage III to IV disease, resulting in reduced disease-free and overall survival in patients treated with anthracycline-based chemotherapy alone. ${ }^{192}$ However, Iqbal et al. ${ }^{193}$ recently reported that the prognostic significance of BCL2 expression in patients treated with chemotherapy alone is subtype-dependent. In the GCB subtype, no difference in overall survival was seen between the BCL2-positive and -negative groups, whereas BCL2 expression was associated with poor survival in the ABC subgroup. Hence, BCL2 expression could be a marker for more aggressive disease in the ABC-DLBCL subtype but not the GCB-DLBCL.

Recent reports have shown that adding rituximab to $\mathrm{CHOP}$ modulates BCL2-associated resistance to chemotherapy. ${ }^{194,195}$ In the GELA study, complete response rates for $\mathrm{R}-\mathrm{CHOP}$ and $\mathrm{CHOP}$ were $78 \%$ and $60 \%$, respectively, for patients with BCL2-positive DLBCL. ${ }^{194}$ The corresponding response rates were $76 \%$ and $73 \%$, respectively, for patients with BCL2negative disease. R-CHOP resulted in significantly better 2-year overall survival rates than CHOP (67\% vs. $48 \%$, respectively) in patients who were BCL2positive, whereas the overall survival rates were not significantly different between the groups among patients who were BCL2-negative (72\% for R-CHOP and $67 \%$ for $\mathrm{CHOP}$ ). Taken together, these results suggest that the addition of rituximab offers a significant survival advantage for patients who are BCL2positive, whereas its effect is limited in those who are BCL2-negative. However, in a re-analysis of the GELA data comparing R-CHOP and CHOP using a competing risk model, Mounier et al. ${ }^{196}$ concluded that rituximab benefited both BCL2-positive and -negative patients. Given the conflicting data, selecting patients for inclusion of rituximab based on BCL2 expression is not appropriate.

BCL6: BCL6 expression is associated with various chromosomal translocations involving chromosome 3q27. In an earlier report, Lossos et al. ${ }^{197}$ identified high expression of BCL6 gene assessed with quanti- 
tative RT-PCR or immunohistochemistry as a favorable factor in patients with DLBCL. In a prospective correlative study, Winter et al. ${ }^{198,199}$ showed that adding rituximab to $\mathrm{CHOP}$ improved failure-free and overall survival in patients who were BCL6-negative, but had no effect on those who were BCL6-positive. This study also showed that BCL6 expression loses its prognostic significance with the addition of rituximab to $\mathrm{CHOP}$, a finding that has now been confirmed by the LLBC (Figure 3). ${ }^{200}$ However, Malumbres et al. ${ }^{185}$ showed that higher expression of BCL6 mRNA was associated with improved survival in patients treated with $\mathrm{R}-\mathrm{CHOP}$, suggesting that BCL6 mRNA versus BCL6 may have different predictive potential.

TP53: The TP53 tumor suppressor gene plays an important role in cell cycle checkpoint, apoptosis, and DNA damage response. Young et al. ${ }^{201}$ recently reported that TP53 mutations in the DNA-binding loops were associated with poor survival in patients with DLBCL treated with anthracycline-based chemotherapy without rituximab, and that these mutations were also predictive of poor overall survival in the GCB subtype but not the non-GCB subtype. High levels of staining for $\mathrm{p} 53$ with absence of p21 staining have been associated with TP53 gene mutations, and have been used as an imperfect surrogate for mutated p53 in some studies. ${ }^{202,203}$ Larger studies are needed to confirm the adverse effect of TP53 mutations identified using sequencing in patients with DLBCL.

p21: $\mathrm{p} 21$ is a downstream effector protein of $\mathrm{p} 53$. In a prospective correlative study, Aurora et al. ${ }^{204}$ showed that p21 expression as determined by immunohistochemistry is predictive of a favorable outcome in older patients with DLBCL treated with R-CHOP but not $\mathrm{CHOP}$. The addition of rituximab to $\mathrm{CHOP}$ improved 5-year failure-free survival for $\mathrm{p} 21$-positive (61\% vs. 24\% for CHOP) but not p21-negative cases (38\% vs. $37 \%$ for $\mathrm{CHOP}$ ). A similar trend was also observed with 5-year overall survival. Among patients treated with R-CHOP, failure-free and overall survival were better for patients who were BCL2negative and $\mathrm{p} 21$-positive compared with those with BCL2-positive and p21-negative phenotype. ${ }^{198}$

LMO2: Lossos et al. ${ }^{183}$ identified the LMO2 gene to be a predictor of survival in patients with GCB-DLBCL subtype. ${ }^{183}$ Natkunam et al. ${ }^{205}$ recently reported that the corresponding protein is expressed in germinal center-derived lymphomas. In the subsequent study, LMO2 expression was identified as a prognostic factor in patients treated with anthracycline-based regimens with or without rituximab. ${ }^{206} \mathrm{LMO} 2 \mathrm{ex}$ pression was significantly correlated with improved overall and progression-free survival; however, the difference in outcome between patients who were LMO2-positive and LMO2-negative was not significantly different among those with high-risk IPI. The combined protein expression of LMO2 and BCL6 correlated with improved outcome in patients treated with $\mathrm{CHOP}$; however, $\mathrm{LMO} 2$ expression was the only predictive marker in patients treated with R-CHOP. 206

Conclusions: Available evidence suggests that changes in the prognostic profile associated with the addition of rituximab to $\mathrm{CHOP}$ likely reflect its impact on survival pathways important to specific subsets of DLBCL, and thereby provide clues to the underlying heterogeneity of the disease.

- The addition of rituximab to CHOP chemotherapy provides greater benefit to patients who are BCL2-positive than those who are BCL2-negative.

- BCL6 expression loses its prognostic significance when rituximab is added to conventional CHOP chemotherapy.

- Patients who are BCL6-negative seem to benefit from rituximab, selectively. The lack of benefit for BCL6-positive cases must be confirmed.

- p21 emerges as a useful prognostic marker in the context of therapy that includes rituximab, and seems to identify a subset of patients who benefit from the addition of rituximab to CHOP.

- The presence of TP53 mutations, especially in the DNA binding loops, is associated with poor survival.

- LMO2 is a strong predictor of improved outcome, and the prognostic significance remains unaffected by the addition of rituximab.

- The prognostic significance of a particular biomarker may depend on the patient population treated and the treatment; therefore, the literature has conflicting reports about the prognostic significance of individual biomarkers.

- Combinations of molecular markers are likely to be more powerful predictors of clinical outcome than single markers.

In the future, biomarker-guided risk-adapted 
A FFS: R-CHOP

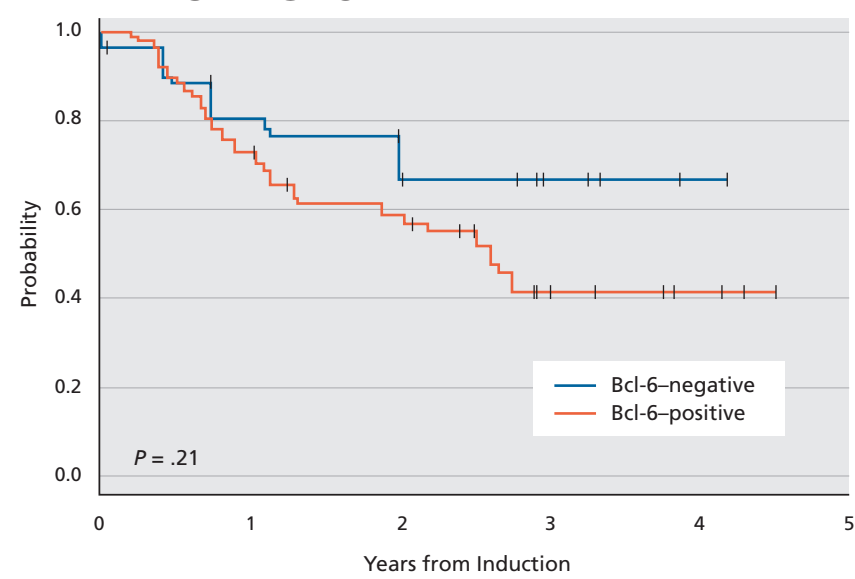

C OS: R-CHOP

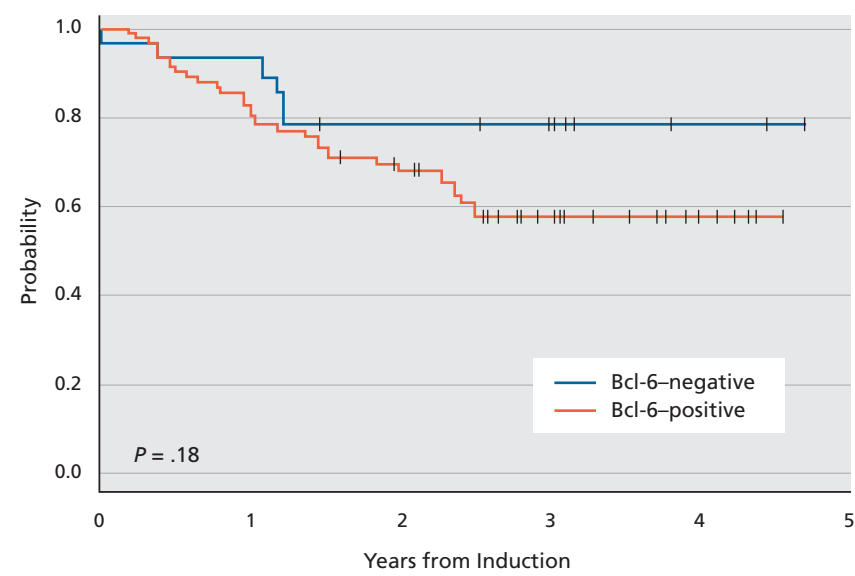

B FFS: CHOP

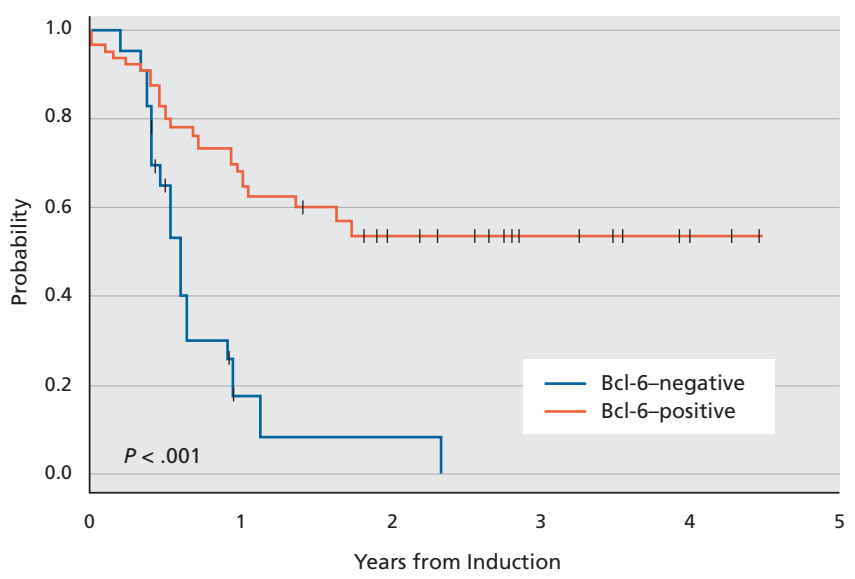

D OS: CHOP

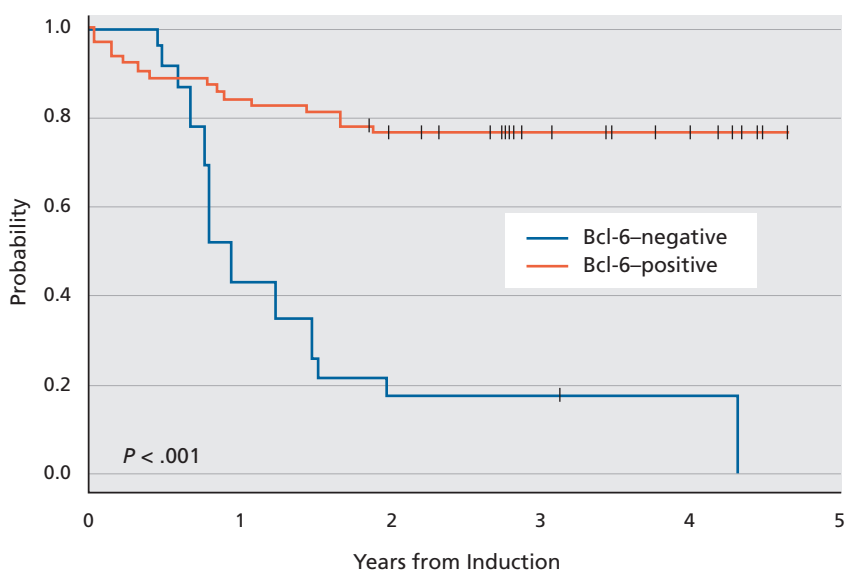

Figure 3 (A, B) Failure-free survival (FFS) and (C, D) overall survival (OS) according to Bcl-6 expression for cases treated on R-CHOP (cyclophosphamide, doxorubicin, vincristine, prednisone, and rituximab) and CHOP (cyclophosphamide, doxorubicin, vincristine, and prednisone) induction arms. Analysis exludes patients who were randomixed to experience molecular remission. From Winter JN, Weller EA, Horning SJ, et al. Prognostic significance of Bcl-6 protein expression in DLCBL treated with CHOP or R-CHOP: a prospective correlative study. Blood 2006;107:4210; with permission.

therapy will be possible. Treatment will be tailored to the specific survival pathways unique to the particular disease subset.

\section{Follicular Lymphoma}

Follicular lymphoma is the most common indolent subtype of NHL, accounting for approximately $22 \%$ of all newly diagnosed cases. Approximately $90 \%$ of these have a $t(14 ; 18)$ translocation, which juxtaposes the BCL2 gene with the IgH locus that results in the deregulated expression of BCL2. No reliable molecular marker exists to predict the clinical course of follicular lymphoma at diagnosis.

Dave et al. ${ }^{207}$ identified 2 gene expression signatures to predict survival in patients with untreated follicular lymphoma. The immune response 1 (IR1) included genes that are expressed in $\mathrm{T}$ cells and macrophages, whereas the immune response 2 (IR2) signature included genes preferentially expressed in macrophages and/or dendritic cells. Increased expression of IR1 signature was associated with a more favorable clinical course and prolonged survival. This study highlights the importance of host/tumor interactions in determining survival. Glas et al. ${ }^{208}$ developed a gene expression profile of 81 genes that can distinguish between indolent and aggressive forms of follicular lymphoma at diagnosis and relapse. Genes that are involved in the cell cycle control, DNA synthesis, and metabolism were up-regulated in the aggressive phase of the disease.

Transformation to DLBCL, which is generally associated with a poor clinical outcome, occurs at 
a rate of approximately $2 \%$ to $3 \%$ per year for at least 15 to 18 years, with the risk for transformation decreasing thereafter. ${ }^{209}$ Various oncogenic mechanisms for the transformation of follicular lymphoma have been described using GEP. ${ }^{208,210-213}$ Lossos et al. ${ }^{210}$ found that only a subset of transformed follicular lymphoma shows increased expression of cMYC and genes regulated by cMYC. Davies et al. ${ }^{213}$ reported that transformed follicular lymphoma was predominantly of the GCB phenotype that evolves by 2 pathways; one is similar to antecedent follicular lymphoma and the other has a higher proliferation rate with activation of the cMYC pathway similar to the group described by Lossos et al. ${ }^{210}$ This latter group is also characterized by the presence of several recurrent genetic abnormalities.

In another study, the transformed follicular lymphoma also exhibited a GCB-like profile. ${ }^{211}$ The authors identified a 3-gene predictor ( $P L A_{2}, P D G F R \alpha$, and Rab-6) for transformation, and also showed that inhibition of p38MAPK blocked the growth of $\mathrm{t}(14 ; 18)$-positive cell lines and of transplanted tumors in NOD-SCID mice, suggesting that pharmacologic targeting of p38MAPK may be an effective treatment strategy.

\section{$\mathrm{MCL}$}

MCL is believed to have the worst characteristics of both indolent and aggressive NHLs. In general, it is believed to be incurable with conventional chemotherapy and to have a more aggressive clinical course than the indolent lymphomas. In most cases, MCL is characterized by the dysregulated expression of cyclin D1, a cell cycle regulatory protein, that results from $\mathrm{t}(11 ; 14)$. Additional genetic alterations have been described in subsets of patients with MCL. ${ }^{214}$ High tumor proliferation indexes (Ki-67), inactivation of INK4a/ARF locus, and TP53 mutations have been associated with shorter survival. ${ }^{214}$

Several GEP studies addressed the heterogeneity of clinical and biologic features in MCL. ${ }^{168,215}$ Rosenwald et al. ${ }^{216}$ identified the proliferation signature as the strongest predictor of survival to date in patients with MCL using GEP of samples derived from 92 patients. The average expression of a signature composed of 20 proliferation signature genes was inversely correlated to survival, with a high statistical significance, and identified patient subsets that differed by more than 5 years in median survival. The authors also showed that it is possible to construct a predictive model from only 4 proliferation signature genes. These findings suggest that therapeutic modulation of the cell cycle has the potential to prolong survival in patients with MCL. Several groups have shown that the $\mathrm{Ki}-67$ expression according to immunohistochemistry provides a surrogate for the proliferation signature and predicts clinical outcome. ${ }^{217-219}$

\section{Conclusions}

- Molecular markers and gene expression signatures that predict clinical outcomes in patients with NHL have been identified.

- Molecular markers must be re-evaluated in the context of each new treatment strategy, because changes in therapy are likely to alter the prognostic significance of established molecular markers.

- Standardization of methods and centralized consensus review are essential if molecular markers are to be used routinely for patient stratification.

- Molecular markers must be validated in large datasets, preferably in prospective uniformly treated patient cohorts. ${ }^{220}$

- GEP has been an important diagnostic tool for classifying DLBCL into at least 3 subtypes that are associated with different prognoses and in the development of gene expression signature models that predict clinical course and survival in patients with follicular lymphoma and MCL. However, this technique is not yet recommended for widespread clinical use. Robust signatures for uncommon groups of NHL are not yet available.

- Development of gene prediction models using routine laboratory techniques, such as quantitative RT-PCR, qNPA, or immunohistochemistry, will facilitate the clinical application of prognostic factors using formalin-fixed or paraffinembedded tissue samples rather than fresh/frozen biopsy specimens.

- Based on available evidence, biomarker-guided risk adapted therapy is currently recommended only in the context of clinical trials.

\section{MRD in NHL}

PCR is used widely for the detection of MRD due to its high diagnostic sensitivity (1 malignant cell among $10^{4}-10^{6}$ normal cells). ${ }^{221}$ Rare event sensitivity ranges from $10^{-4}$ to $10^{-6}$ for the analysis of fusion-gene transcripts; $10^{-5}$ to $10^{-6}$ for the analysis of chromosomal translocation; and $10^{-3}$ to $10^{-4}$ for the analysis of $\mathrm{IgH}$ and/or TCR gene rearrangements. 


\section{Follicular Lymphoma}

Detection of $\boldsymbol{t}(14 ; 18)$ translocation: The $t(14 ; 18)$ translocation (resulting in the overexpression of BCL2) is a characteristic genetic marker in approximately $90 \%$ of patients with follicular lymphoma and is commonly used for the quantitative detection of MRD using PCR. However, this translocation is not detectable in the remaining $10 \%$ to $20 \%$ of patients with follicular lymphoma using other available methods, such as FISH, suggesting that other mechanisms are involved in the dysregulated expression of BCL2 in this subset of patients. ${ }^{3}$

The $\mathrm{t}(14 ; 18)$ translocation occurs at multiple breakpoints. The breakpoints on chromosome 14 occur in the heavy chain joining region $\left(\mathrm{J}_{\mathrm{H}}\right)$ or the heavy chain diversity segments $\left(D_{H}\right)$. Most of the breakpoints on chromosome 18 are tightly clustered into 2 regions: major breakpoint cluster region (MBR), which occurs in approximately $60 \%$ of cases, and the minor breakpoint cluster region ( $\mathrm{mcr}$ ), which occurs in approximately $25 \%$ of cases. ${ }^{3}$ PCR assays using $\mathrm{MBR} / \mathrm{J}_{\mathrm{H}}$ or $\mathrm{mcr} / \mathrm{J}_{\mathrm{H}}$ primer sets can detect the translocation in $65 \%$ of cases. ${ }^{222}$ Real-time PCR is more suitable than qualitative PCR for detecting MRD in bone marrow and peripheral blood and in stem cell harvests to assess the efficacy of in vivo purging before autologous stem cell transplant (ASCT). ${ }^{166,223}$ The sensitivity of real-time PCR ranges from $10^{-5}$ to $10^{-6}$. Long-distance PCR assay significantly enhances the detection rate of $t(14 ; 18) .224$ However, it requires high-quality DNA and is not routinely used in laboratories.

Recent studies have identified the presence of additional breakpoint clusters, referred to as 3' BCL2, 5' mcr, and an intermediate cluster region (icr). Weinberg et al. ${ }^{225}$ reported that the frequency of icr breakpoint is significantly higher compared with mor ( $13 \%$ vs. $5 \%$, respectively) in patients with follicular lymphoma. A higher detection rate for $\mathrm{t}(14 ; 18)$ can be obtained through analyzing icr with standard PCR assays, as shown by Albinger-Hegyi et al. ${ }^{226}$ The multiplex PCR assay can detect the translocation in $88 \%$ of patients with follicular lymphoma using primer sets capable of detecting translocations in MBR, mcr, and 2 other specific regions between MBR and mcr. ${ }^{227}$

The presence of a clonal rearrangement in nonmalignant cells (e.g., BCL2/IgH rearrangement in "normal" individuals) may result in a false-positive
MRD if the sensitivity of PCR assay is extremely high. ${ }^{228,229}$ Residual t(14;18)-positive cells may not be clonogenic cells, and the optimal timing and frequency of monitoring MRD is not known. 230

In an international multicenter, collaborative study, nested PCR was more sensitive than singleround PCR for detecting BCL2/IgH rearrangements, with a false-positive rate of $28 \% .{ }^{231}$ The results of a more recent collaborative study showed that the sensitivity for quantitative PCR had less variation with no false-positives. ${ }^{232}$

Quantitative PCR is potentially more useful in the clinical setting than conventional PCR. The standard or real-time PCR assays will only detect breakpoints within the 2 cluster regions (MBR and mcr). In clinical trials, using PCR assays with primer sets capable of detecting additional BCL2 breakpoint regions is essential for the reliable identification of MRD. In patients with follicular lymphoma in whom $t(14 ; 18)$ translocation is not present $(10 \%-20 \%)$ or in whom the breakpoints of the rearrangement occur outside of regions detected by currently used PCR assays, rearrangements of variable, diversity, and joining segments (VDJ) of $\mathrm{IgH}$ gene are used for MRD detection. $^{233}$

MRD After Chemotherapy: Molecular assessment of $\mathrm{t}(14 ; 18)$-positive cells in the peripheral blood and bone marrow has been studied over the past 2 decades in follicular lymphoma. In the pre-rituximab era, bone marrow was considered to be a better tissue source than peripheral blood for detecting MRD, because bone marrow is more likely to be positive even after the rapid clearance of $\mathrm{t}(14 ; 18)$-positive cells from peripheral blood. ${ }^{234,235}$ The choice of tissue source is of great significance for monitoring MRD, because the rate of clearance of residual cells varies among tissue compartments (peripheral blood, bone marrow, and lymph nodes). The clearance of residual tumor cells from the tested site must reflect the systemic disease burden for the reliable identification of MRD.

In the chemotherapy era, half or fewer patients with follicular lymphoma remained PCR-positive after a full course of treatment, suggesting that conventional therapy did not eradicate BCL2-positive cells. ${ }^{236}$ Some studies have shown correlation between MRD and clinical outcome in patients treated with chemotherapy. ${ }^{237,238}$ Molecular response as assessed using PCR in peripheral blood was identified 
as one of the prognostic factors to predict failure-free survival. In patients with advanced stage follicular lymphoma, those who achieved a molecular response and sustained it during the first year of treatment with anthracycline-based chemotherapy had a significantly longer failure-free survival than those who did not (4-year failure-free survival: $76 \%$ and $38 \%$, respectively). ${ }^{237}$

The achievement of molecular response also correlated with outcome in patients treated with CVP (cyclophosphamide, vincristine, prednisone) chemotherapy in conjunction with interferon alfa. ${ }^{238}$ At 2-year follow-up, continuous clinical remission was observed in $94 \%$ of patients with undetectable MRD (PCR-negative), whereas $50 \%$ of patients who reverted to PCR-positivity had relapsed disease.

However, other studies have shown persistence of $\mathrm{t}(14 ; 18)$-positive cells in patients with advanced follicular lymphoma experiencing long-term remissions after CVP chemotherapy. ${ }^{239}$ In another prospective study, first-line treatment with CVP chemotherapy with interferon resulted in rapid clearance of $\mathrm{t}(14 ; 18)$-positive cells from peripheral blood irrespective of the clinical response. ${ }^{240}$

MRD After B-Cell-Targeted Therapy: Rituximab alone or in combination with chemotherapy is associated with a rapid clearance of residual tumor cells. However, early data suggested that MRD assessment in the single-agent rituximab era was less predictive. ${ }^{241-245}$

In the pivotal study of single-agent rituximab, $\mathrm{t}(14 ; 18)$-positive cells were rapidly cleared from the peripheral blood and bone marrow, but most patients still had evidence of residual nodal disease, suggesting the presence of a "compartmental effect" in patients receiving single-agent rituximab. ${ }^{241}$ Ghielmini et $a .^{244}$ showed that the clearance of circulating $\mathrm{t}(14 ; 18)$-positive cells was significantly associated with clinical response, whereas in another study, PCR-negativity in peripheral blood and/or bone marrow samples after rituximab did not correlate with clinical response. ${ }^{245}$

Czuczman et al. ${ }^{246}$ first reported that the addition of rituximab to $\mathrm{CHOP}$ chemotherapy induced durable clinical and molecular remissions in patients with untreated low-grade follicular lymphoma. Complete nodal remission was documented in all of the patients who became BCL2-negative in the bone marrow and peripheral blood after treatment with CHOP plus rituximab. ${ }^{241}$ At 9-year follow-up, 7 of 8 patients who were found to be BCL2-positive in peripheral blood and bone marrow converted to PCR-negative status after completion of therapy. ${ }^{247}$

The results of 3 randomized clinical trials showed the prognostic significance of achieving MRD and the higher rate of MRD achieved with chemotherapy plus rituximab. ${ }^{248-250}$

Pott et al. ${ }^{248}$ showed that circulating lymphoma cells in peripheral blood at diagnosis and follow-up after treatment with $\mathrm{CHOP}$ or R-CHOP correlated with time to treatment failure (TTF). Patients with a lymphoma load greater than 0.01 had a significantly lower TTF than those with lymphoma load of 0.01 or less. R-CHOP removed residual lymphoma cells more efficiently ( $>2$ logs) than $\mathrm{CHOP}$ inducing a molecular remission in $76 \%$ of patients. Patients who achieved molecular remission after induction therapy had improved progression-free survival at 2 years (90\% vs. $53 \%$ for patients who were MRD-positive). CHOP induced a reduction of approximately 2 logs, but $77 \%$ of patients remained MRD-positive.

In the trial conducted by the German study group, approximately $75 \%$ to $85 \%$ of patients treated with a full course of R-CHOP cleared the bone marrow and peripheral blood of $\mathrm{t}(14 ; 18)$-positive cells as assessed with real-time quantitative PCR. The log clearance or rate of reduction $(\geq 2 \mathrm{log}$ ) of circulating tumor cells was more predictive of disease-free and progression-free survival. ${ }^{250}$

In the GITMO trial, Ladetto et al. ${ }^{249}$ compared rituximab-supplemented high-dose sequential chemotherapy (R-HDS) with ASCT and R-CHOP as first-line therapy in high-risk patients. MRD analysis using PCR showed that the patients in both groups who achieved molecular remission (PCR-negative) had a better PFS than those without molecular remission (Figure 4A). Molecular remission was achieved in $44 \%$ of patients receiving $\mathrm{R}-\mathrm{CHOP}$ and $80 \%$ of patients in the R-HDS group. The progression free survival for the entire study population (without considering PCR status) was significantly higher in favor of R-HDS, because it is associated with increased number of molecular remissions. However, the outcome of patients achieving molecular remission was similar regardless of the treatment as was the outcome of patients not achieving molecular remission (Figures 4B and 4C).

Molecular remission after sequential admin- 
istration of $\mathrm{CHOP}$ and rituximab was also associated with a better clinical outcome. ${ }^{251}$ Patients who achieved clinical response after $\mathrm{CHOP}$ but remained PCR-positive were treated with rituximab. At 12 weeks follow-up, 59\% converted to PCR-negative in peripheral blood and bone marrow, and $63 \%$ were PCR negative at 44 weeks follow-up. Freedom from recurrence was $57 \%$ in patients who were PCR-negative compared with only $20 \%$ in patients who lost molecular negativity. These results showed the predictive value of additional therapy with rituximab in patients who were PCR-positive after chemotherapy. MRD After High-Dose Therapy and ASCT With or Without Rituximab: Gribben et al..$^{252}$ first reported the prognostic significance of monitoring MRD after ASCT. The presence of BCL2-positive residual lymphoma cells identified patients who are at high risk for relapse. In a more recent report, Hirt et al. ${ }^{253}$ also showed that after ASCT, increasing numbers of circulating $\mathrm{t}(14 ; 18)$-positive cells is associated with relapse, and complete remission is associated with stable cell counts.

Freedman et al. ${ }^{254,255}$ reported the best results regarding the correlation of clinical outcome and PCR status of bone marrow in patients with follicular lymphoma in first remission after ASCT using in vitro purging with monoclonal antibodies. With more than 10 years of follow-up, ASCT results in follicular lymphoma continue to show the prognostic significance of achieving MRD after ASCT in both patients in first remission and the transplanted cells assessed ex vivo. ${ }^{256,257}$ At 12 -year follow-up, the

results suggest that a subset of patients whose bone marrow was PCR-negative for $\mathrm{t}(14 ; 18)$ have prolonged survival. Bone marrow involvement at harvest and PCR-detectable disease in the bone marrow after purging were identified as predictors of decreased progression-free survival. ${ }^{256}$

In vivo purging with rituximab during the process of stem cell harvest has been used in several studies to obtain $\mathrm{t}(14 ; 18)$-negative stem cell grafts. ${ }^{258}$ Recent studies have reported better progression-free survival and molecular remissions after in vivo purging with rituximab before ASCT; ${ }^{259,260}$ it produced $86 \%$ of harvests free of contamination compared with only $14 \%$ in the control group. All patients who were re-infused with negative stem cell grafts at transplantation experienced complete remission with significantly better 5-year progression-free survival $(100 \%)$ compared with those reinfused with contaminated samples $(41 \%){ }^{259}$

\section{$\mathrm{MCL}$}

Detection of $\boldsymbol{t}(\mathbf{1 1}$;14) Translocation: The $\mathrm{t}(11 ; 14)$ translocation is detectable in $70 \%$ to $100 \%$ of patients with MCL. Most of the breakpoints on chromosome 14 occur in the $\mathrm{J}_{\mathrm{H}}$ region. Although the breakpoints are widely scattered on chromosome 11, 3 clusters have been identified so far. The most important one is referred to as major translocation cluster region (BCL1-MTC), which contains up to $50 \%$ of the translocations and has been a suitable target for detecting MRD. ${ }^{4}$

The translocations involving the MTC region are detectable by PCR in $30 \%$ to $40 \%$ of the cases. ${ }^{3}$ PCR

A

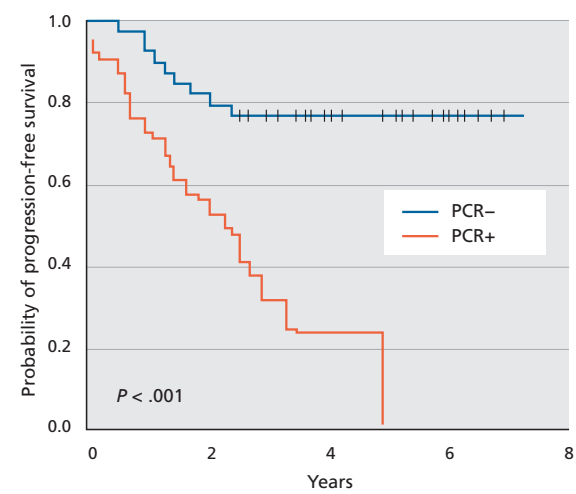

B

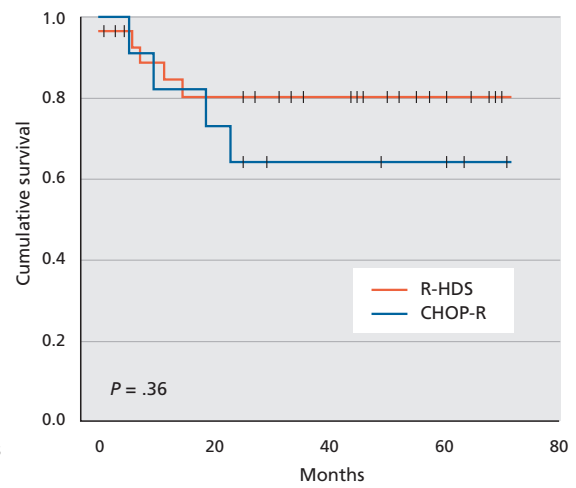

C

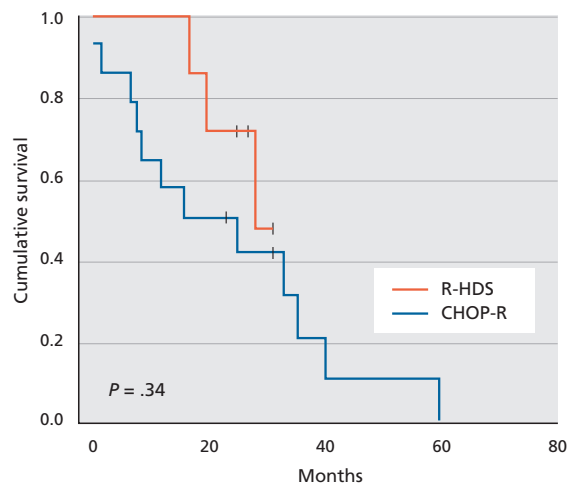

Figure 4 (A) Progression-free survival according to the presence of molecular remission (PCR-) or lack of molecular remission $(\mathrm{PCR}+)$. (B) Progression-free survival according to treatment arm in patients experiencing molecular remission. (C) Progression-free survival according to treatment arm in patients not experiencing molecular remission. From Ladetto M, De Marco F, Benedetti F, et al. Prospective, multicenter randomized GITMO/IIL trial comparing intensive (R-HDS) versus conventional (CHOP-R) chemoimmunotherapy in high-risk follicular lymphoma at diagnosis: the superior disease control of R-HDS does not translate into an overall survival advantage. Blood 2008;111:4009; with permission. 
detection of $\mathrm{t}(11 ; 14)$ is performed by nested PCR analysis using a consensus primer derived from the $\mathrm{J}_{\mathrm{H}}$ regions and 2 primer sets for the MTC region. ${ }^{4}$ This can detect 1 malignant cell out of $10^{5}$ normal cells. Bottcher et al. ${ }^{261}$ recently showed that qualitative consensus IGH-PCR is more sensitive than FCI for detecting MRD. Real-time quantitative PCR targeting the $B C L 1 / J_{H}$ rearrangement was also more sensitive than the qualitative PCR assay for the detection of tumor burden in the BM. ${ }^{262}$

Alternatively, quantitative monitoring of cyclin D1 overexpression has been used for the detection of MRD in patients with MCL. ${ }^{263}$

MRD After B-Cell Targeted Therapy: Unlike follicular lymphoma, PCR-negative status has been more difficult to achieve in patients with MCL. The addition of rituximab to $\mathrm{CHOP}$ resulted in the clearance of residual disease from peripheral blood and bone marrow in only $36 \%$ of patients with newly diagnosed MCL, but the molecular remission rates after induction therapy did not translate into prolonged progression-free survival (16.5 months for those who did not experience molecular remission and 18.8 months for those who did) ${ }^{264}$ However, the results of a recent randomized trial showed that achievement of molecular remission after immunochemotherapy might predict treatment response in patients with MCL. ${ }^{265}$ Remission duration was significantly improved in patients who were MRD-negative in bone marrow compared with those who were MRD-positive (100\% vs. $66 \%$, respectively, at 24 months).

MRD After High-Dose Therapy and ASCT With or Without Rituximab: Pott et al. ${ }^{266}$ reported that MRD status after ASCT is a powerful indicator of treatment outcome in patients with advanced-stage MCL. ${ }^{266}$ The MRD-negative group had a median progression-free survival of 92 months compared with 21 months in the MRD-positive group. Cytarabine-based regimens and myeloablative radiochemotherapy significantly reduced MRD compared with CHOP-like regimens.

Recent studies incorporating high-dose chemotherapy, rituximab, and transplantation suggest that molecular remission after ASCT is associated with improved outcome in a significant portion of patients with MCL. Ladetto et al. ${ }^{267}$ evaluated the importance of monitoring of MRD in patients who had molecular relapse after R-HDS and ASCT. PCR-negative status was restored after 4 to 6 courses of rituximab in all patients who experienced molecular relapse after $\mathrm{R}$ -
HDS and ASCT. This was observed even in patients who had previously received several courses of rituximab, suggesting that the residual tumor cells are still sensitive to rituximab.

The results of 2 multicenter trials have shown the prognostic significance of rituximab-supplemented high-dose therapy with in vivo rituximab-purged ASCT. ${ }^{268,269}$ In vivo purging resulted in PCR-negative stem cell products in all patients with evaluable markers and was also associated with long-term progression-free survival and remission. These results must be confirmed in prospective trials.

\section{Limitations of Monitoring MRD}

Both clinical and laboratory criteria must be established for the successful implementation of MRD monitoring in routine clinical practice. Robust laboratory assays must be in place to allow the sensitive and specific detection of the biomarker. Development of robust laboratory-based assays facilitates the necessary clinical comparisons for validating a biomarker for MRD detection.

Timing of specimen sampling is crucial in the prognostic value of MRD detection, as is definition of the optimal reservoir for MRD evaluation dependent on the treatment modality, and location within the reservoir sampled being a particular consideration with specimens exhibiting results at the low end of the reporting range of the respective assay. ${ }^{270}$

Standardization of all phases of specimen testing is crucial. In the preanalytic phase, analyte and matrix stability, storage time, and temperature are practical considerations that can affect the overall performance of specimen testing. For RNA-based assays, the inherent instability of the analyte dictates particular care, with suggested use of RNA stabilization agents during specimen collection. ${ }^{271}$

In the analytic phase, assay accuracy, precision, and reproducibility; reportable ranges; and analytic sensitivity and specificity are important criteria that must be standardized. European and international groups have pioneered the standardization of reagents and methods (flow cytometry immunophenotyping and quantitative PCR-based assays), ${ }^{272-275}$ rendering useful resources and guidelines for the implementation of MRD monitoring.

For the postanalytic phase, when data are interpreted, reference intervals/cutoff values are determined and reports generated, guidelines also must be implemented to ensure interlaboratory uniformi- 
ty. $271,273,276,277$ Assurance of uniformity could be provided by the introduction of standard calibrators and strict proficiency testing programs.

\section{Conclusions}

Although MRD detection in NHL has been under investigation for many years, immense clinical, pathologic, and molecular heterogeneity that is inherently displayed in this disease and its subtypes have presented difficulties in implementing uniform standardized assays and have impeded the development of robust molecular markers.

Molecular markers for MRD detection in NHL currently being evaluated display variable efficacy in the informative detection of MRD, depending on the treatment modality. Assessment of MRD is technically feasible for most patients.

Incorporation of MRD assessment into clinical practice and interpretation of data needs standardization, quantification of MRD assessment, and uniform reporting at serial time-points from all laboratories. Typically, biomarkers are discovered in small data sets, validated in several retrospective trials, and then evaluated in large prospective trials. The correlation between MRD status and outcome must be established in well-designed, large, prospective, randomized clinical trials performed within the auspices of consortiums and/or collaborative study groups. Changing therapeutic approaches or agents must be accompanied by re-evaluation of the respective MRD biomarker.

\section{MicroRNAs in Leukemias and Lymphomas}

MicroRNAs (miRNAs) are short noncoding, singlestranded RNAs that play a role in gene regulation. ${ }^{278-280}$ miRNA genes are mostly transcribed by RNA polymerase II in the nucleus to form a large RNA precursor called primary miRNA, which is transformed to a mature 21-22-nucleotide miRNA through a multistep process in the nucleus and cytoplasm. miRNAs bind to the mRNA-containing complementary nucleotide sequence, resulting in the degradation of mRNA or inhibition of protein translation.

miRNAs have been shown to occur in the genome regions of cancer cells involved in deletion or amplification of chromosomes. ${ }^{281}$ Tumor suppressor miRNAs are located in the deleted regions of the genome and are usually down-regulated in cancer cells and control oncogene expression. Oncogenic miRNAs are located in the amplified region of the genome and are usually up-regulated in cancer cells and enable the upregulation of tumor suppressor genes. miRNAs have been used in diagnostics and prognostication for various hematologic malignancies. ${ }^{282,283}$

Initial work showed that miRNA expression signatures can accurately discriminate ALL from AML, ${ }^{284}$ and among cytogenetic and molecular subsets of AML. ${ }^{285-287}$ Furthermore, it was demonstrated that miRNA signatures are associated with AML prognosis. ${ }^{288}$ For example, patients with high expression of miR-191 and miR-199a had significantly worse overall and event-free survival than AML patients with low expression. Similar findings were described in ALL. ${ }^{289,290}$

Calin et al. ${ }^{291}$ first showed that miRNA-15a and miRNA-16-1 are located in the region of chromosome $13 \mathrm{q} 14$ and are deleted in most patients with chronic lymphocytic leukemia (CLL), indicating that miRNAs are involved in the pathogenesis. miRNAs have also been shown to regulate the expression of BCL2 and TCL1 in patients with CLL. miRNA-15a and -16-1 negatively regulate BCL2 expression and promote apoptosis in leukemic cell lines. ${ }^{292,293}$ TCL expression is inversely correlated with that of miRNA-29b and $-181 b .{ }^{294}$ miRNA signatures are also associated with prognosis and disease progression in patients with CLL. ${ }^{295,296}$ Calin et al. ${ }^{296}$ identified a signature composed of 13 miRNAs that differentiated patients with favorable and unfavorable prognosis based on the ZAP-70 expression and $\mathrm{IgV}_{\mathrm{H}}$ mutational status. Of the 13 miRNAs, 9 were overexpressed in the group of patients with a short interval from diagnosis to the start of initial therapy. miRNA-155 and its host gene BIC have been reported to accumulate in human B-cell lymphomas. ${ }^{297-299}$ Higher copy numbers of miRNA-155 and elevated expression of BIC RNA have been found in lymphoma cells compared with normal circulating B cells. ${ }^{297}$ miRNAs could also be useful as molecular markers for the differentiation of DLBCL subtypes. ${ }^{297,300,301}$ ABC phenotype is characterized by the higher expression of miRNA-155.297,301 Lawrie et al. ${ }^{300}$ also identified 2 additional miRNAs ( -21 and -221) that were more highly expressed in ABC-type than GCB-type. This study also showed that miRNAs can be measured reliably from routine paraffinembedded biopsies of archived samples.

\section{Conclusions}

- miRNA technology has the potential not only to improve the ability to predict outcome and 
differentiate clinically distinct subtypes but may also identify new therapeutic targets.

- Quantification and standardization of expression analysis is essential to establish a library of miRNA signatures that can be used in clinical trials for diagnosing and treating cancer.

\section{References}

1. Diamandis EP, Fritsche HA, Lilja H, et al., eds. Tumor Markers: Physiology, Pathobiology, Technology and Clinical Applications. Washington, DC: AACC Press; 2002.

2. Drexler HG, MacLeod RA, Borkhardt A, Janssen JW. Recurrent chromosomal translocations and fusion genes in leukemialymphoma cell lines. Leukemia 1995;9:480-500.

3. Vega F, Medeiros LJ. Chromosomal translocations involved in non-Hodgkin lymphomas. Arch Pathol Lab Med 2003;127:11481160 .

4. Faderl S, Kurzrock R, Estrov Z. Minimal residual disease in hematologic disorders. Arch Pathol Lab Med 1999;123:1030 1034.

5. Corradini P, Ladetto M, Pileri A, Tarella C. Clinical relevance of minimal residual disease monitoring in non-Hodgkin's lymphomas: a critical reappraisal of molecular strategies. Leukemia 1999;13:1691-1695.

6. Bruggemann M, Pott C, Ritgen M, Kneba M. Significance of minimal residual disease in lymphoid malignancies. Acta Haematol 2004;112:111-119.

7. Kulasingam V, Diamandis EP. Strategies for discovering novel cancer biomarkers through utilization of emerging technologies. Nat Clin Pract Oncol 2008;5:588-599.

8. Sehn LH. Optimal use of prognostic factors in non-Hodgkin lymphoma. Hematology Am Soc Hematol Educ Program 2006:295-302.

9. Faderl SA, Talpaz M, Estrov Z et al. The biology of chronic myeloid leukemia. N Engl J Med 1999;341:164-172.

10. Radich JP, Dai H, Mao M, et al. Gene expression changes associated with progression and response in chronic myeloid leukemia. Proc Natl Acad Sci U S A 2006;103:2794-2799.

11. Sawyers CL. Chronic myeloid leukemia. N Engl J Med 1999;340:1330-1340.

12. O'Brien SG, Guilhot F, Larson RA et al. Imatinib compared with interferon and low-dose cytarabine for newly diagnosed chronic-phase chronic myeloid leukemia. N Engl J Med 2003;348:994-1004.

13. Jabbour E, Cortes JE, Giles FJ, et al. Current and emerging treatment options in chronic myeloid leukemia. Cancer 2007;109:2171-2181.

14. Hochhaus A, Druker B, Sawyers C, et al. Favorable long-term follow-up results over 6 years for response, survival, and safety with imatinib mesylate therapy in chronic-phase chronic myeloid leukemia after failure of interferon-alpha treatment. Blood 2008;111:1039-1043.

15. O'Brien SG, Guilhot F, Goldman JM, et al. International randomized study of interferon versus STI571 (IRIS) 7-year follow-up: sustained survival, low rate of transformation and increased rate of major molecular response (MMR) in patients (pts) with newly diagnosed chronic myeloid leukemia in chronic phase (CMLCP) treated with imatinib (IM) [abstract]. Blood 2008;112:Abstract 186.

16. Kantarjian H, O'Brien S, Talpaz M, et al. Outcome of patients with Philadelphia chromosome-positive chronic myelogenous leukemia post-imatinib mesylate failure. Cancer 2007;109:15561560.

17. Hochhaus A, Kantarjian HM, Baccarani M, et al. Dasatinib induces notable hematologic and cytogenetic responses in chronic-phase chronic myeloid leukemia after failure of imatinib therapy. Blood 2007;109:2303-2309.

18. Kantarjian HM, Giles F, Gattermann N, et al. Nilotinib (formerly AMN107), a highly selective BCR-ABL tyrosine kinase inhibitor, is effective in patients with Philadelphia chromosome positive chronic myelogenous leukemia in chronic phase following imatinib resistance and intolerance. Blood 2007;110:3540-3546.

19. Martinelli G, Iacobucci I, Soverini S, et al. Monitoring minimal residual disease and controlling drug resistance in chronic myeloid leukaemia patients in treatment with imatinib as a guide to clinical management. Hematol Oncol 2006;24:196-204.

20. Kantarjian H, Schiffer C, Jones D, Cortes J. Monitoring the response and course of chronic myeloid leukemia in the modern era of BCR-ABL tyrosine kinase inhibitors: practical advice on the use and interpretation of monitoring methods. Blood 2008;111:1774-1780.

21. Landstrom A, Tefferi A. Fluorescent in situ hybridization in the diagnosis, prognosis, and treatment monitoring of chronic myeloid leukemia. Leuk Lymphoma 2006;47:397-402.

22. Douet-Guilbert N, Morel F, Le Charpentier T, et al. Interphase FISH for follow-up of Philadelphia chromosome-positive chronic myeloid leukemia treatment. Anticancer Res 2004;24:2535-2539.

23. Seong DC, Kantarjian HM, Ro JY, et al. Hypermetaphase fluorescence in situ hybridization for quantitative monitoring of Philadelphia chromosome-positive cells in patients with chronic myelogenous leukemia during treatment. Blood 1995;86:23432349.

24. Dewald GW, Wyatt WA, Juneau AL, et al. Highly sensitive fluorescence in situ hybridization method to detect double BCR/ $\mathrm{ABL}$ fusion and monitor response to therapy in chronic myeloid leukemia. Blood 1998;91:3357-3365.

25. Druker BJ, Guilhot F, O'Brien SG, et al. Five-year follow-up of patients receiving imatinib for chronic myeloid leukemia. $\mathrm{N}$ Engl J Med 2006;355:2408-2417.

26. Guilhot F, Larson RA, O'Brien SG, et al. Time to complete cytogenetic response (CCyR) does not affect long-term outcomes for patients on imatinib therapy [abstract]. Blood 2007;110:Abstract 27.

27. de Lavallade H, Apperley JF, Khorashad JS, et al. Imatinib for newly diagnosed patients with chronic myeloid leukemia: incidence of sustained responses in an intention-to-treat analysis. J Clin Oncol 2008;26:3358-3363.

28. Kantarjian HM, Quintas-Cardama A, O'Brien S, et al. Importance of early intervention with dasatinib at cytogenetic rather than hematologic resistance to imatinib [abstract]. Blood 2007;110:Abstract 1036.

29. Tam CS, Kantarjian H, Garcia-Manero G, et al. Failure to achieve a major cytogenetic response by 12 months defines inadequate response in patients receiving nilotinib or dasatinib as second or subsequent line therapy for chronic myeloid leukemia. Blood 2008;112:516-518.

30. Baccarani M, Rosti G, Saglio G, et al. Dasatinib time to and durability of major and complete cytogenetic response (MCyR 
and $\mathrm{CCyR}$ ) in patients with chronic myeloid leukemia in chronic phase (CML-CP) [abstract]. Blood 2008;112:Abstract 450.

31. Branford S, Hughes TP, Rudzki Z. Monitoring chronic myeloid leukaemia therapy by real-time quantitative PCR in blood is a reliable alternative to bone marrow cytogenetics. Br J Haematol 1999;107:587-599.

32. Kantarjian H, Talpaz M, Cortes J, et al. Quantitative polymerase chain reaction monitoring of $\mathrm{BCR}-\mathrm{ABL}$ during therapy with imatinib mesylate (STI571; gleevec) in chronic-phase chronic myelogenous leukemia. Clin Cancer Res 2003;9:160-166.

33. Baccarani M, Saglio G, Goldman, J et al. Evolving concepts in the management of chronic myeloid leukemia: recommendations from an expert panel on behalf of the European LeukemiaNet. Blood 2006;108:1809-1820.

34. Hughes T, Deininger M, Hochhaus A, et al. Monitoring CML patients responding to treatment with tyrosine kinase inhibitors: review and recommendations for harmonizing current methodology for detecting BCR-ABL transcripts and kinase domain mutations and for expressing results. Blood 2006;108:2837.

35. Jabbour E, Cortes J, Hagop M, Kantarjian H. Molecular monitoring in chronic myeloid leukemia. Cancer 2008;112:2112-2118.

36. Press RD, Love Z, Tronnes AA, et al. BCR-ABL mRNA levels at and after the time of a complete cytogenetic response (CCR) predict the duration of CCR in imatinib mesylate treated patients with CML. Blood 2006;107:4250-4256.

37. Press RD, Galderisi C, Yang R, et al. A half-log increase in BCR-ABL RNA predicts a higher risk of relapse in patients with chronic myeloid leukemia with an imatinib-induced complete cytogenetic response. Clin Cancer Res 2007;13:6136-6143.

38. Cortes J, Talpaz M, O'Brien S, et al. Molecular responses in patients with chronic myelogenous leukemia in chronic phase treated with imatinib mesylate. Clin Cancer Res 2005;11:34253432 .

39. Iacobucci I, Saglio G, Rosti G, et al. Achieving a major molecular response at the time of a complete cytogenetic response predicts a better duration of $\mathrm{CCgR}$ in imatinib-treated chronic myeloid leukemia patients. Clin Cancer Res 2006;12:3037-3042.

40. Kantarjian HM, Talpaz M, O'Brien S, et al. Survival benefit with imatinib mesylate versus interferon-alpha-based regimens in newly diagnosed chronic-phase chronic myelogenous leukemia. Blood 2006;108:1835-1840.

41. Marin D, Milojkovic D, Olavarria E, et al. European LeukemiaNet criteria for failure or suboptimal response reliably identify patients with CML in early chronic phase treated with imatinib whose eventual outcome is poor. Blood 2008;112:4437-4444.

42. Kantarjian HM, Shan J, Jones D, et al. Significance of rising levels of minimal residual disease in patients with philadelphia chromosome-positive chronic myelogenous leukemia ( $\mathrm{Ph}+\mathrm{CML})$ in complete cytogenetic response (CGCR) [abstract]. Blood 2008;112:Abstract 445.

43. Branford S, Lawrence R, Fletcher L, et al. The initial molecular response of chronic phase CML patients treated with second generation $\mathrm{ABL}$ inhibitor therapy after imatinib failure can predict inadequate response and provide indications for rational mutation screening [abstract]. Blood 2008;112:Abstract 331.

44. Milojkovic D, Bua M, Apperley JF, et al. Prediction of cytogenetic response to second generation TKI therapy in CML chronic phase patients who have failed imatinib therapy and early identification of factors that influence survival [abstract]. Blood 2008;112:Abstract 332.
45. Radich JP, Gehly G, Gooley T, et al. Polymerase chain reaction detection of the BCR-ABL fusion transcript after allogeneic marrow transplantation for chronic myeloid leukemia: results and implications in 346 patients. Blood 1995;85:2632-2638.

46. Radich JP, Gooley T, Bryant E, et al. The significance of bcr-abl molecular detection in chronic myeloid leukemia patients "late," 18 months or more after transplantation. Blood 2001;98:17011707.

47. Olavarria E, Kanfer E, Szydlo R, et al. Early detection of BCR-ABL transcripts by quantitative reverse transcriptasepolymerase chain reaction predicts outcome after allogeneic stem cell transplantation for chronic myeloid leukemia. Blood 2001;97:1560-1565.

48. Apperley JF. Part I: mechanisms of resistance to imatinib in chronic myeloid leukaemia. Lancet Oncol 2007;8:1018-1029.

49. Gambacorti-Passerini C, Zucchetti M, Russo D, et al. Alpha1 acid glycoprotein binds to imatinib (STI571) and substantially alters its pharmacokinetics in chronic myeloid leukemia patients. Clin Cancer Res 2003;9:625-632.

50. Larson RA, Druker BJ, Guilhot F, et al. Imatinib pharmacokinetics and its correlation with response and safety in chronic-phase chronic myeloid leukemia: a subanalysis of the IRIS study. Blood 2008;111:4022-4028.

51. Picard S, Titier K, Etienne G, et al. Trough imatinib plasma levels are associated with both cytogenetic and molecular responses to standard-dose imatinib in chronic myeloid leukemia. Blood 2007;109:3496-3499.

52. Ault P, Kantarjian HM, Bryan J, et al. Clinical use of imatinib plasma levels in patients with chronic myeloid leukemia (CML) [abstract]. Blood 2008;112:Abstract 4255.

53. Thomas J, Wang L, Clark RE, Pirmohamed M. Active transport of imatinib into and out of cells: implications for drug resistance. Blood 2004;104:3739-3745.

54. White DL, Saunders VA, Dang P, et al. Most CML patients who have a suboptimal response to imatinib have low OCT-1 activity: higher doses of imatinib may overcome the negative impact of low OCT-1 activity. Blood 2007;110:4064-4072.

55. White DL, Saunders VA, Dang P, et al. CML patients with low OCT-1 activity achieve better molecular responses on high dose imatinib than on standard dose. Those with high OCT-1 activity have excellent responses on either dose: a TOPS correlative study [abstract]. Blood 2008;112:Abstract 3187.

56. Giannoudis A, Davies A, Lucas CM, et al. Effective dasatinib uptake may occur without human organic cation transporter 1 (hOCT1): implications for the treatment of imatinib-resistant chronic myeloid leukemia. Blood 2008;112:3348-3354.

57. White DL, Saunders VA, Dang P, et al. OCT-1-mediated influx is a key determinant of the intracellular uptake of imatinib but not nilotinib (AMN107): reduced OCT-1 activity is the cause of low in vitro sensitivity to imatinib. Blood 2006;108:697-704.

58. Deininger MWN, O'Brien SG, Ford JM, Druker BJ. Practical management of patients with chronic myeloid leukemia receiving imatinib. J Clin Oncol 2003;21:1637-1647.

59. Gorre ME, Mohammed M, Ellwood K, et al. Clinical resistance to STI- 571 cancer therapy caused by BCR-ABL gene mutation or amplification. Science 2001;293:876-880.

60. Hochhaus A, Kreil S, Corbin AS, et al. Molecular and chromosomal mechanisms of resistance to imatinib (STI571) therapy. Leukemia 2002;16:2190-2196.

61. Branford S, Rudzki Z, Parkinson I, et al. Real time quantitative PCR analysis can be used as a primary screen to identify patients 
Molecular Markers in Leukemias and Lymphomas

with CML treated with imatinib who have BCR-ABL kinase domain mutations. Blood 2004;104:2926-2932.

62. Khorashad JS, de Lavallade H, Apperley JF, et al. Finding of kinase domain mutations in patients with chronic phase chronic myeloid leukemia responding to imatinib may identify those at high risk of disease progression. J Clin Oncol 2008;26:4806-4813.

63. Soverini S, Martinelli G, Rosti G, et al. ABL mutations in late chronic phase chronic myeloid leukemia patients with up-front cytogenetic resistance to imatinib are associated with a greater likelihood of progression to blast crisis and shorter survival: a study by the GIMEMA Working Party on Chronic Myeloid Leukemia. J Clin Oncol 2005;23:4100-4109.

64. Nicolini FE, Corm S, Le QH, et al. Mutation status and clinical outcome of 89 imatinib mesylate-resistant chronic myelogenous leukemia patients: a retrospective analysis from the French intergroup of CML (Fi(phi)-LMC GROUP). Leukemia 2006;20:1061-1106.

65. Soverini S, Colarossi S, Gnani A, et al. Contribution of ABL kinase domain mutations to imatinib resistance in different subsets of Philadelphia-positive patients: by the GIMEMA Working Party on Chronic Myeloid Leukemia. Clin Cancer Res 2006;12:7374-7379.

66. Branford S, Rudzki Z, Walsh S, et al. Detection of BCR-ABL mutations in patients with CML treated with imatinib is virtually always accompanied by clinical resistant and mutation in the ATP phosphate-binding loop are associated with a poor prognosis. Blood 2003;102:276-283.

67. Jabbour E, Kantarjian H, Jones D, et al. Frequency and clinical significance of BCR-ABL mutations in patients with chronic myeloid leukemia treated with imatinib mesylate. Leukemia 2006;20:1767-1773.

68. Cortes J, Rousselot P, Kim DW, et al. Dasatinib induces complete hematologic and cytogenetic responses in patients with imatinibresistant or -intolerant chronic myeloid leukemia in blast crisis. Blood 2007;109:3207-3213.

69. Guilhot F, Apperley J, Kim DW, et al. Dasatinib induces significant hematologic and cytogenetic responses in patients with imatinibresistant or -intolerant chronic myeloid leukemia in accelerated phase. Blood.2007;109:4143-4150.

70. Nicolini FE, Hayette S, Corm S, et al. Clinical outcome of 27 imatinib mesylate-resistant chronic myelogenous leukemia patients harboring a T315I BCR-ABL mutation. Haematologica 2007;92:1238-1241.

71. Jabbour E, Kantarjian H, Jones D, et al. Characteristics and outcomes of patients with chronic myeloid leukemia and T315I mutation following failure of imatinib mesylate therapy. Blood 2008;112:53-55.

72. O'Dwyer ME, Mauro MJ, Blasdel C, et al. Clonal evolution and lack of cytogenetic response are adverse prognostic factors for hematologic relapse of chronic phase CML patients treated with imatinib mesylate. Blood 2004;103:451-455.

73. O'Dwyer ME, Mauro MJ, Kurilik G, et al. The impact of clonal evolution on response to imatinib mesylate (STI571) in accelerated phase CML. Blood 2002;100:1628-1633.

74. Cortes JE, Talpaz M, Giles F, et al. Prognostic significance of cytogenetic clonal evolution in patients with chronic myelogenous leukemia on imatinib mesylate therapy. Blood 2003;101:37943800.

75. Fialkow PJ, Jacobson RJ, Papayannopoulou T. Chronic myelocytic leukemia: Clonal origin in a stem cell common to the granulocyte, erythrocyte, platelet and monocyte/macrophage. Am J Med 1977;63:125-130.

76. Huff CA, Matsui WH, Smith BD, Jones RJ. Strategies to eliminate cancer stem cells: clinical implications. Eur J Cancer 2006;42:1293-1297.

77. Jiang X, Zhao Y, Forrest D, et al. Stem cell biomarkers in chronic myeloid leukemia. Dis Markers 2008;24:201-216.

78. Kavalerchik E, Goff D, Jamieson CHM. Chronic myeloid leukemia stem cells. J Clin Oncol 2008;26:2911-2915.

79. Jamieson $\mathrm{CH}$. Chronic myeloid leukemia stem cells. Hematology Am Soc Hematol Educ Program 2008:436-442.

80. Holyoake T, Jiang X, Eaves C, Eaves A. Isolation of a highly quiescent subpopulation of primitive leukemic cells in chronic myeloid leukemia. Blood 1999;94:2056-2064.

81. Graham SM, Jorgensen HG, Allan E, et al. Primitive, quiescent, Philadelphia-positive stem cells from patients with chronic myeloid leukemia are insensitive to STI571 in vitro. Blood 2002;99:319-325.

82. Holtz MS, Slovak ML, Zhang F, et al. Imatinib mesylate (STI571) inhibits growth of primitive malignant progenitors in chronic myelogenous leukemia through reversal of abnormally increased proliferation. Blood 2002;99:3792-3800.

83. Valent P, Deininger M. Clinical perspectives of concepts on neoplastic stem cells and stem cell-resistance in chronic myeloid leukemia. Leuk Lymphoma 2008;49:604-609.

84. Angstreich G, Matsui W, Huff C, et al. Effects of imatinib and interferon on primitive chronic myeloid leukaemia progenitors. Br J Haematol 2005;130:373-381.

85. Bedi A, Zehnbauer B, Collector $\mathrm{M}$, et al. BCR-ABL gene rearrangement and expression of primitive hematopoietic progenitors in chronic myeloid leukemia. Blood 1993;81:28982902.

86. Gerber JM, Qin L, Matsui W, et al. Expression of potential therapeutic targets by leukemic stem cells [abstract]. Proceedings of the 99th Annual Meeting of American Association for Cancer Research; April 12-16, 2008; San Diego, California. Abstract LB88.

87. Yong ASM, Szydlo RM, Goldman JM, et al. Molecular profiling of CD34+ cells identifies low expression of CD7, along with high expression of proteinase 3 or elastase, as predictors of longer survival in patients with CML. Blood 2006;107:205-212.

88. Yong ASM, Rezvani K, Savani BN, et al. High PR3 or ELA2 expression by CD34+ cells in advanced-phase chronic myeloid leukemia is associated with improved outcome following allogeneic stem cell transplantation and may improve PR1 peptide-driven graft-versus-leukemia effects. Blood 2007;110:770-775.

89. Epping MT, Bernards R. A causal role for the human tumor antigen preferentially expressed antigen of melanoma in cancer. Cancer Res 2006;66:10639-10642.

90. Paydas S, Tanriverdi K, Yavuz S, et al. PRAME mRNA levels in cases with chronic leukemia: clinical importance and review of the literature. Leuk Res 2007;31:365-369.

91. Paydas S, Tanriverdi K, Yavuz S. et al. PRAME mRNA levels in cases with acute leukemia: clinical importance and future prospects. Am J Hematol 2005;79:257-261.

92. Watari $K$, Tojo A, Nagamura-Inoue $T$, et al. Identification of a melanoma antigen, PRAME, as a BCR/ABL-inducible gene. FEBS Lett 2000;466:367-371.

93. Oehler V, Cummings C, Sabo K, et al. Preferentially expressed antigen in melanoma (PRAME) expression in normal and CML 
CD34+ progenitor cells impairs myeloid differentiation [abstract]. Blood 2008;112:Abstract 1071.

94. Mrozek K, Marcucci G, Paschka P, et al. Clinical relevance of mutations and gene-expression changes in adult acute myeloid leukemia with normal cytogenetics: are we ready for a prognostically prioritized molecular classification? Blood 2007;109:431-448.

95. Tobal K, Johnson PR, Saunders MJ, et al. Detection of CBFB/ MYH11 transcripts in patients with inversion and other abnormalities of chromosome 16 at presentation and remission. Br J Haematol 1995;91:104-108.

96. Marcucci G, Caligiuri MA, Bloomfield CD. Core binding factor (CBF) acute myeloid leukemia: is molecular monitoring by RTPCR useful clinically? Eur J Haematol 2003;71:143-154.

97. Schoch C, Schnittger S, Klaus M, et al. AML with 11q23/MLL abnormalities as defined by the WHO classification: incidence, partner chromosomes, FAB subtype, age distribution, and prognostic impact in an unselected series of 1897 cytogenetically analyzed AML cases. Blood 2003;102:2395-2402.

98. Lo-Coco F, Ammatuna E, Montesinos P, Sanz MA. Acute promyelocytic leukemia: recent advances in diagnosis and management. Semin Oncol 2008;35:401-409.

99. Marcucci G, Caligiuri MA, Dohner H, et al. Quantification of CBFbeta/MYH11 fusion transcript by real time RT-PCR in patients with $\operatorname{INV}(16)$ acute myeloid leukemia. Leukemia 2001;15:1072-1080.

100. Lane S, Saal R, Mollee P, et al. A > or $=1$ log rise in RQ-PCR transcript levels defines molecular relapse in core binding factor acute myeloid leukemia and predicts subsequent morphologic relapse. Leuk Lymphoma 2008;49:517-523.

101. Stentoft J, Hokland P, Ostergaard M, et al. Minimal residual core binding factor AMLs by real time quantitative PCR—initial response to chemotherapy predicts event free survival and close monitoring of peripheral blood unravels the kinetics of relapse. Leuk Res 2006;30:389-395.

102. Paschka P, Marcucci G, Ruppert AS, et al. Adverse prognostic significance of KIT mutations in adult acute myeloid leukemia with inv(16) and t(8;21): a Cancer and Leukemia Group B Study. J Clin Oncol 2006;24:3904-3911.

103. Cairoli R, Beghini A, Grillo G, et al. Prognostic impact of c-KIT mutations in core binding factor leukemias: an Italian retrospective study. Blood 2006;107:3463-3468.

104. Marcucci G, Livak KJ, Bi W, et al. Detection of minimal residual disease in patients with AML1/ETO-associated acute myeloid leukemia using a novel quantitative reverse transcription polymerase chain reaction assay. Leukemia 1998;12:1482-1489.

105. Weisser M, Kern W, Schoch C, et al. Risk assessment by monitoring expression levels of partial tandem duplications in the MLL gene in acute myeloid leukemia during therapy. Haematologica 2005;90:881-889.

106. Mitterbauer G, Zimmer C, Pirc-Danoewinata H, et al. Monitoring of minimal residual disease in patients with MLL-AF6-positive acute myeloid leukaemia by reverse transcriptase polymerase chain reaction. Br J Haematol 2000;109:622-628.

107. Takatsuki H, Yufu Y, Tachikawa Y, Uike N. Monitoring minimal residual disease in patients with MLL-AF6 fusion transcriptpositive acute myeloid leukemia following allogeneic bone marrow transplantation. Int J Hematol 2002;75:298-301.

108. Scholl C, Schlenk RF, Eiwen K, et al. The prognostic value of MLL-AF9 detection in patients with $\mathrm{t}(9 ; 11)(\mathrm{p} 22 ; \mathrm{q} 23)$-positive acute myeloid leukemia. Haematologica 2005;90:1626-1634.
109. Stirewalt DL, Radich JP. The role of FLT3 in haematopoietic malignancies. Nat Rev Cancer 2003;3:650-665.

110. Ferrara F, Palmieri S, Leoni F. Clinically useful prognostic factors in acute myeloid leukemia. Crit Rev Oncol Hematol 2008;66:181-193.

111. Schnittger S, Schoch C, Dugas M, et al. Analysis of FLT3 length mutations in 1003 patients with acute myeloid leukemia: correlation to cytogenetics, FAB subtype, and prognosis in the AMLCG study and usefulness as a marker for the detection of minimal residual disease. Blood 2002;100:59-66.

112. Shih LY, Huang CF, Wu JH, et al. Internal tandem duplication of FLT3 in relapsed acute myeloid leukemia: a comparative analysis of bone marrow samples from 108 adult patients at diagnosis and relapse. Blood 2002;100:2387-2392.

113. Kottaridis PD, Gale RE, Langabeer SE, et al. Studies of FLT3 mutations in paired presentation and relapse samples from patients with acute myeloid leukemia: implications for the role of FLT3 mutations in leukemogenesis, minimal residual disease detection, and possible therapy with FLT3 inhibitors. Blood 2002;100:2393-2398.

114. Cloos J, Goemans BF, Hess CJ, et al. Stability and prognostic influence of FLT3 mutations in paired initial and relapsed AML samples. Leukemia 2006;20:1217-1220.

115. Dohner K, Schlenk RF, Habdank M, et al. Mutant nucleophosmin (NPM1) predicts favorable prognosis in younger adults with acute myeloid leukemia and normal cytogenetics: interaction with other gene mutations. Blood 2005;106:3740-3746.

116. Thiede C, Koch S, Creutzig E, et al. Prevalence and prognostic impact of NPM1 mutations in 1485 adult patients with acute myeloid leukemia (AML). Blood 2006;107:4011-4020.

117. Gorello P, Cazzaniga G, Alberti F, et al. Quantitative assessment of minimal residual disease in acute myeloid leukemia carrying nucleophosmin (NPM1) gene mutations. Leukemia 2006;20:1103-1108.

118. Chou WC, Tang JL, Wu SJ, et al. Clinical implications of minimal residual disease monitoring by quantitative polymerase chain reaction in acute myeloid leukemia patients bearing nucleophosmin (NPM1) mutations. Leukemia 2007;21:9981004.

119. Palmisano M, Grafone T, Ottaviani E, et al. NPM1 mutations are more stable than FLT3 mutations during the course of disease in patients with acute myeloid leukemia. Haematologica 2007;92:1268-1269.

120. Inoue $K$, Ogawa $H$, Yamagami $T$, et al. Long-term follow-up of minimal residual disease in leukemia patients by monitoring WT1 (Wilms tumor gene) expression levels. Blood 1996;88:2267-2278.

121. Cilloni D, Gottardi E, De Micheli D, et al. Quantitative assessment of WT1 expression by real time quantitative PCR may be a useful tool for monitoring minimal residual disease in acute leukemia patients. Leukemia 2002;16:2115-2121.

122. Ogawa $H$, Tamaki $H$, Ikegame $K$, et al. The usefulness of monitoring WT1 gene transcripts for the prediction and management of relapse following allogeneic stem cell transplantation in acute type leukemia. Blood 2003;101:1698-1704.

123. Garg M, Moore H, Tobal K, Liu Yin JA. Prognostic significance of quantitative analysis of WT1 gene transcripts by competitive reverse transcription polymerase chain reaction in acute leukaemia. Br J Haematol 2003;123:49-59.

124. Ostergaard M, Olesen LH, Hasle H, et al. WT1 gene expression: an excellent tool for monitoring minimal residual disease in $70 \%$ 
of acute myeloid leukaemia patients - results from a single-centre study. Br J Haematol 2004;125:590-600.

125. Barragan E, Cervera J, Bolufer P, et al. Prognostic implications of Wilms' tumor gene (WT1) expression in patients with de novo acute myeloid leukemia. Haematologica 2004;89:926-933.

126. Weisser M, Kern W, Rauhut S, et al. Prognostic impact of RTPCR-based quantification of WT1 gene expression during MRD monitoring of acute myeloid leukemia. Leukemia 2005;19:14161423.

127. Hamalainen MM, Kairisto V, Juvonen V, et al. Wilms tumour gene 1 overexpression in bone marrow as a marker for minimal residual disease in acute myeloid leukaemia. Eur J Haematol 2008;80:201-207.

128. Candoni A, Tiribelli M, Toffoletti E, et al. Quantitative assessment of WT1 gene expression after allogeneic stem cell transplantation is a useful tool for monitoring minimal residual disease in acute myeloid leukemia. Eur J Haematol 2009;82:61-68.

129. Gaiger A, Schmid D, Heinze G, et al. Detection of the WT1 transcript by RT-PCR in complete remission has no prognostic relevance in de novo acute myeloid leukemia. Leukemia 1998;12:1886-1894.

130. Barragan E, Pajuelo JC, Ballester S, et al. Minimal residual disease detection in acute myeloid leukemia by mutant nucleophosmin (NPM1): comparison with WT1 gene expression. Clin Chim Acta 2008;395:120-123.

131. Larson RA. Management of acute lymphoblastic leukemia in older patients. Semin Hematol 2006;43:126-133.

132. van der Velden VH, Cazzaniga G, Schrauder A, et al. Analysis of minimal residual disease by $\mathrm{Ig} / \mathrm{TCR}$ gene rearrangements: guidelines for interpretation of real-time quantitative PCR data. Leukemia 2007;21:604-611.

133. van Dongen JJ, Wolvers-Tettero IL. Analysis of immunoglobulin and T cell receptor genes. Part II: possibilities and limitations in the diagnosis and management of lymphoproliferative diseases and related disorders. Clin Chim Acta 1991;198:93-174.

134. Beishuizen A, Verhoeven MA, Mol EJ, et al. Detection of immunoglobulin heavy-chain gene rearrangements by Southern blot analysis: recommendations for optimal results. Leukemia 1993; 7:2045-2053.

135. Szczepanski T, Beishuizen A, Pongers-Willemse MJ, et al. Crosslineage $T$ cell receptor gene rearrangements occur in more than ninety percent of childhood precursor-B acute lymphoblastic leukemias: alternative PCR targets for detection of minimal residual disease. Leukemia 1999;13:196-205.

136. Breit TM, Wolvers-Tettero IL, Beishuizen A, et al. Southern blot patterns, frequencies, and junctional diversity of T-cell receptordelta gene rearrangements in acute lymphoblastic leukemia. Blood 1993;82:3063-3074.

137. van der Velden VH, Hochhaus A, Cazzaniga G, et al. Detection of minimal residual disease in hematologic malignancies by realtime quantitative PCR: principles, approaches, and laboratory aspects. Leukemia 2003;17:1013-1034.

138. Mortuza FY, Papaioannou M, Moreira IM, et al. Minimal residual disease tests provide an independent predictor of clinical outcome in adult acute lymphoblastic leukemia. J Clin Oncol 2002;20:1094-1104.

139. Bruggemann $M$, Raff $T$, Flohr $T$, et al. Clinical significance of minimal residual disease quantification in adult patients with standard-risk acute lymphoblastic leukemia. Blood 2006;107:1116-1123.
140. Lee S, Kim DW, Cho B, et al. Risk factors for adults with Philadelphia-chromosome-positive acute lymphoblastic leukaemia in remission treated with allogeneic bone marrow transplantation: the potential of real-time quantitative reversetranscription polymerase chain reaction. $\mathrm{Br} \mathrm{J}$ Haematol 2003;120:145-153.

141. Gleissner B, Rieder H, Thiel E, et al. Prospective BCR-ABL analysis by polymerase chain reaction (RT-PCR) in adult acute B-lineage lymphoblastic leukemia: reliability of RT-nested-PCR and comparison to cytogenetic data. Leukemia 2001;15:18341840.

142. Radich JP. Molecular measurement of minimal residual disease in Philadelphia-positive acute lymphoblastic leukaemia. Best Pract Res Clin Haematol 2002;15:91-103.

143. Stirewalt DL, Guthrie KA, Beppu L, et al. Predictors of relapse and overall survival in Philadelphia chromosome-positive acute lymphoblastic leukemia after transplantation. Biol Blood Marrow Transplant 2003;9:206-212.

144. Yanada M, Sugiura I, Takeuchi J, et al. Prospective monitoring of BCR-ABL1 transcript levels in patients with Philadelphia chromosome-positive acute lymphoblastic leukaemia undergoing imatinib-combined chemotherapy. Br J Haematol 2008;143:503510.

145. Olivero S, Maroc C, Beillard E, et al. Detection of different Ikaros isoforms in human leukaemias using real-time quantitative polymerase chain reaction. Br J Haematol 2000;110:826-830.

146. Paulsson K, Cazier JB, MacDougall F, et al. Microdeletions are a general feature of adult and adolescent acute lymphoblastic leukemia: unexpected similarities with pediatric disease. Proc Natl Acad Sci U S A 2008;105:6708-6713.

147. Mullighan CG, Miller CB, Radtke I, et al. BCR-ABL1 lymphoblastic leukaemia is characterized by the deletion of Ikaros. Nature 2008;453:110-114.

148. Iacobucci I, Lonetti A, Cilloni D, et al. Identification of different Ikaros cDNA transcripts in Philadelphia-positive adult acute lymphoblastic leukemia by a high-throughput capillary electrophoresis sizing method. Haematologica 2008;93:18141821.

149. Iacobucci I, Lonetti A, Messa F, et al. Expression of spliced oncogenic Ikaros isoforms in Philadelphia-positive acute lymphoblastic leukemia patients treated with tyrosine kinase inhibitors: implications for a new mechanism of resistance. Blood 2008;112:3847-3855.

150. The International Non Hodgkin's Lymphoma Prognostic Factors Project. A predictive model for aggressive non Hodgkin's lymphoma. N Engl J Med 1993;329:987-994.

151. Solal Celigny P, Pascal R, Colombat P, et al. Follicular lymphoma international prognostic index. Blood 2004;104:1258-1265.

152. Hoster E, Dreyling M, Klapper W, et al. A new prognostic index (MIPI) for patients with advanced-stage mantle cell lymphoma. Blood 2008;111:558-565

153. Dunphy CH. Applications of flow cytometry and immunohistochemistry to diagnostic hematopathology. Arch Pathol Lab Med 2004;128:1004-1022.

154. de Jong D, Rosenwald A, Chhanabhai M, et al. Immunohistochemical prognostic markers in diffuse large B-cell lymphoma: validation of tissue microarray as a prerequisite for broad clinical applications-a study from the Lunenburg Lymphoma Biomarker Consortium. J Clin Oncol 2007;25:805812. 
155. Kaleem Z. Flow cytometric analysis of lymphomas: current status and usefulness. Arch Pathol Lab Med 2006;130:1850-1858.

156. Craig FE, Foon KA. Flow cytometric immunophenotyping for hematologic neoplasms. Blood 2008;111;3941-3967.

157. Douglas VK, Gordon LI, Goolsby CL, et al. Lymphoid aggregates in bone marrow mimic residual lymphoma after rituximab therapy for non-Hodgkin lymphoma. Am J Clin Pathol 1999;112:844853.

158. Campbell LJ. Cytogenetics of lymphomas. Pathology 2005;37:493-507.

159. Ventura RA, Martin-Subero JI, Jones M, et al. FISH analysis for the detection of lymphoma-associated chromosomal abnormalities in routine paraffin-embedded tissue. J Mol Diagn 2006;8:141-151.

160. Sreekantaish C. FISH panels for hematologic malignancies. Cytogenet Genome Res 2007;118:284-296.

161. Poetsch M, Weber-Matthiesen K, Plendl HJ, et al. Detection of the $\mathrm{t}(14 ; 18)$ chromosomal translocation by interphase cytogenetics with yeast-artificial-chromosome probes in follicular lymphoma and nonneoplastic lymphoproliferation. J Clin Oncol 1996;14:963-969.

162. Sanchez-Izquierdo D, Siebert R, Harder L, et al. Detection of translocations affecting the BCL6 locus in B cell non-Hodgkin's lymphoma by interphase fluorescence in situ hybridization. Leukemia 2001;15:1475-1484.

163. Kallioniemi A, Kallioniemi OP, Sudar D, et al. Comparative genomic hybridization for molecular cytogenetic analysis of solid tumors. Science 1992;258:818-821.

164. Pinkel D, Segraves R, Sudar D, et al. High resolution analysis of DNA copy number variation using comparative genomic hybridization to microarrays. Nat Genet 1998;20:207-211.

165. Drexler HG, Borkhardt A, Janssen JW. Detection of chromosomal translocations in leukemia-lymphoma cells by polymerase chain reaction. Leuk Lymphoma 1995;19:359-380.

166. Gu K, Chan WC, Hawley RC. Practical detection of $\mathrm{t}(14 ; 18)$ (IgH/BCL2) in follicular lymphoma. Arch Pathol Lab Med 2008;132:1355-1361.

167. Mocellin S, Rossi CR, Pilati P, et al. Quantitative real-time PCR: a powerful ally in cancer research. Trends Mol Med 2003;9:189195.

168. Leich E, Hartmann EM, Burek C, et al. Diagnostic and prognostic significance of gene expression profiling in lymphomas. APMIS 2007;115:1135-1146.

169. Brazma A, Hingamp P, Quackenbush J, et al. Minimum information about a microarray experiment (MIAME)-toward standards for microarray data. Nat Genet 2001;29;365-371.

170. MAQC Consortium, Shi L, Reid LH, et al. The MicroArray Quality Control (MAQC) project shows inter-and intraplatform reproducibility of gene expression measurements. Nat Biotechnol 2006;24:1151-1161.

171. Shi L, Jones W, Jensen R, et al. The balance of reproducibility, sensitivity, and specificity of lists of differentially expressed genes in microarray studies. BMC Bioinformatics 2008;9(Suppl 9):S10.

172. Ebert BL, Golub TR. Genomic approaches to hematologic malignancies. Blood 2004;104:923-932.

173. Lossos IS, Morgensztern D. Prognostic biomarkers in diffuse large B-cell lymphoma. J Clin Oncol 2006;24:995-1007.

174. Abramson JS, Shipp MA. Advances in the biology and therapy of diffuse large B-cell lymphoma: moving toward a molecularly targeted approach. Blood 2005;106:1164-1174.
175. Alizadeh AA, Eisen MB, Davis RE, et al. Distinct types of diffuse large B-cell lymphoma identified by gene expression profiling. Nature 2000;403:503-511.

176. Wright G, Tan B, Rosenwald A, et al. A gene expression-based method to diagnose clinically distinct subgroups of diffuse large B cell lymphoma. Proc Natl Acad Sci U S A 2003;100:9991-9996.

177. Lenz G, Wright GW, Emre NC, et al. Molecular subtypes of diffuse large B-cell lymphoma arise by distinct genetic pathways. Proc Natl Acad Sci U S A 2008;105:13520-13525.

178. Rosenwald A, Wright G, Chan WC, et al. The use of molecular profiling to predict survival after chemotherapy for diffuse largeB-cell lymphoma. N Engl J Med 2002;346:1937-1947.

179. Rimsza LM, Roberts RA, Miller TP, et al. Loss of MHC class II gene and protein expression in diffuse large B-cell lymphoma is related to decreased tumor immunosurveillance and poor patient survival regardless of other prognostic factors: a follow-up study from the Leukemia and Lymphoma Molecular Profiling Project. Blood 2004;103:4251-4258.

180. Lenz G, Wright G, Dave SS, et al. Stromal gene signatures in large-B-cell lymphomas. N Engl J Med 2008;359:2313-2323.

181. Lenz $G$, Wright $G$, Dave $S$, et al. Molecular signatures implicate ilmmune cells, fibrosis, and angiogenesis in survival following R-CHOP treatment of diffuse large B cell lymphoma [abstract]. Blood 2008;112:Abstract 475.

182. Hans CP, Weisenburger DD, Greiner TC, et al. Confirmation of the molecular classification of diffuse large B-cell lymphoma by immunohistochemistry using a tissue microarray. Blood 2004;103:275-282.

183. Lossos IS, Czerwinski DK, Alizadeh AA, et al. Prediction of survival in diffuse large-B-cell lymphoma based on the expression of six genes. N Engl J Med 2004;350:1828-1837.

184. Rimsza LM, LeBlanc ML, Unger JM, et al. Gene expression predicts overall survival in paraffin-embedded tissues of diffuse large B-cell lymphoma treated with R-CHOP. Blood 2008;112:3425-3433.

185. Malumbres R, Chen J, Tibshirani R, et al. Paraffin-based 6-gene model predicts outcome in diffuse large B-cell lymphoma patients treated with R-CHOP. Blood 2008;111:5509-5514.

186. Choi WWL, Weisenburger DD, Greiner TC, et al. A new immunostain algorithm classifies diffuse large B-cell lymphoma into molecular subtypes with high accuracy. Clin Cancer Res 2009; in press.

187. Fu K, Weisenburger DD, Choi WWL, et al. Addition of rituximab to standard chemotherapy improves the survival of both the germinal center B-cell-like and non-germinal center B-celllike subtypes of diffuse large B-cell lymphoma. J Clin Oncol 2008;26:4587-4594.

188. Nyman H, Adde M, Karjalainen-Lindsberg ML, et al. Prognostic impact of immunohistochemically defined germinal center phenotype in diffuse large B-cell lymphoma patients treated with immunochemotherapy. Blood 2007;109:4930-4935.

189. Lenz G, Wright $G$, Dave $S$, et al. Gene expression signatures predict overall survival in diffuse large B cell lymphoma treated with rituximab and CHOP-like chemotherapy [abstract]. Blood 2007;110:Abstract 348.

190. Iqbal J, Sanger WG, Horsman DE, et al. BCL2 translocation defines a unique tumor subset within the germinal center B-celllike diffuse large B-cell lymphoma. Am J Pathol 2004;165:159166.

191. Huang JZ, Sanger WG, Greiner TC, et al. The $t(14 ; 18)$ defines a unique subset of diffuse large B-cell lymphoma with a germinal center B-cell gene expression profile. Blood 2002;99:2285-2290. 
192. Gascoyne RD, Adomat SA, Krajewski S, et al. Prognostic significance of $\mathrm{Bcl}-2$ protein expression and $\mathrm{Bcl}-2$ gene rearrangement in diffuse aggressive non-Hodgkin's lymphoma. Blood 1997;90:244-251.

193. Iqbal J, Neppalli VT, Wright G, et al. BCL2 expression is a prognostic marker for the activated B-cell-like type of diffuse large B-cell lymphoma. J Clin Oncol 2006;24:961-968.

194. Mounier N, Briere J, Gisselbrecht C, et al. Rituximab plus CHOP (R-CHOP) overcomes bcl-2-associated resistance to chemotherapy in elderly patients with diffuse large B-cell lymphoma (DLBCL). Blood 2003;101:4279-4284.

195. Wilson KS, Sehn LH, Berry B, et al. CHOP-R therapy overcomes the adverse prognostic influence of BCL-2 expression in diffuse large B-cell lymphoma. Leuk Lymphoma 2007;48:1102-1109.

196. Mounier N, Briere J, Gisselbrecht C, et al. Estimating the impact of rituximab on bcl-2-associated resistance to $\mathrm{CHOP}$ in elderly patients with diffuse large B-cell lymphoma. Haematologica 2006;91:715-716.

197. Lossos IS, Jones CD, Warnke R, et al. Expression of a single gene, BCL-6, strongly predicts survival in patients with diffuse large B-cell lymphoma. Blood 2001;98:945-951.

198. Winter JN, Zhang L, Li S, et al. P21, BCL-2, and the IPI, but not BCL-6, predict clinical outcome in DLBCL treated with rituximab-CHOP: long-term follow-up from E4494 [abstract]. Ann Oncol 2008;19(Suppl 4):Abstract 51.

199. Winter JN, Weller EA, Horning SJ, et al. Prognostic significance of Bcl-6 protein expression in DLBCL treated with $\mathrm{CHOP}$ or R-CHOP: a prospective correlative study. Blood 2006;107:42074213.

200. The Lunenburg Lymphoma Biomarker Consortium (LLBC). First results of an international study to establish a new clinicobiological prognostic index for diffuse large B-cell lymphoma (DLBCL) [abstract]. Ann Oncol 2008;19(Suppl 4):Abstract 54 bis.

201. Young KH, Leroy K, Moller MB, et al. Structural profiles of TP53 gene mutations predict clinical outcome in diffuse large B-cell lymphoma: an international collaborative study. Blood 2008;112:3088-3098.

202. Chilosi M, Doglioni C, Magalini A, et al. p21/WAF1 cyclinkinase inhibitor expression in non-Hodgkin's lymphomas: a potential marker of p53 tumor-suppressor gene function. Blood 1996;88:4012-4020.

203. Young $\mathrm{KH}$, Weisenburger $\mathrm{DD}$, Dave BJ, et al. Mutations in the DNA-binding codons of TP53, which are associated with decreased expression of TRAILreceptor-2, predict for poor survival in diffuse large B-cell lymphoma. Blood 2007;110:43964405.

204. Aurora V, Li S, Horning SJ, et al. Prognostic significance of $\mathrm{p} 53 /$ p21 expression in DLBCL treated with CHOP or R-CHOP: a correlative study of E4494 [abstract]. J Clin Oncol 2007;25(Suppl 1):Abstract 8038 .

205. Natkunam Y, Zhao S, Mason DY, et al. The oncoprotein LMO2 is expressed in normal germinal-center B cells and in human B-cell lymphomas. Blood 2007;109:1636-1642.

206. Natkunam Y, Farinha P, Hsi ED, et al. LMO2 protein expression predicts survival in patients with diffuse large B-cell lymphoma treated with anthracycline-based chemotherapy with and without rituximab. J Clin Oncol 2008;26:447-454.

207. Dave SS, Wright G, Tan B, et al. Prediction of survival in follicular lymphoma based on molecular features of tumor-infiltrating immune cells. N Engl J Med 2004;351:2159-2169.
208. Glas AM, Kersten MJ, Delahaye LJ, et al. Gene expression profiling in follicular lymphoma to assess clinical aggressiveness and to guide the choice of treatment. Blood 2005;105:301-307.

209. Al-Tourah AJ, Chhanabhai M, Hoskins PJ, et al. Transformed lymphoma: incidence and long-term outcome [abstract]. Blood 2004;104:Abstract 3253.

210. Lossos IS, Alizadeh AA, Diehn M, et al. Transformation of follicular lymphoma to diffuse large-cell lymphoma: alternative patterns with increased or decreased expression of c-myc and its regulated genes. Proc Natl Acad Sci U S A 2002;99:8886-8891.

211. Elenitoba-Johnson KSJ, Jenson SD, Abbott RT, et al. Involvement of multiple signaling pathways in follicular lymphoma transformation: p38-mitogen-activated protein kinase as a target for therapy. Proc Natl Acad Sci U S A 2003;100:7259-7264.

212. Martinez-Climent JA, Alizadeh AA, Segraves R, et al. Transformation of follicular lymphoma to diffuse large cell lymphoma is associated with a heterogeneous set of DNA copy number and gene expression alterations. Blood 2003;101:3109_ 3117.

213. Davies AJ, Rosenwald A, Wright G, et al. Transformation of follicular lymphoma to diffuse large B-cell lymphoma proceeds by distinct oncogenic mechanisms. Br J Haematol 2007;136:286293.

214. Fernandez V, Hartmann E, Ott G, et al. Pathogenesis of mantlecell lymphoma: all oncogenic roads lead to dysregulation of cell cycle and DNA damage response pathways. J Clin Oncol 2005;23:6364-6369.

215. Hartmann E, Fernandez V, Moreno V, et al. Five-gene model to predict survival in mantle-cell lymphoma using frozen or formalinfixed, paraffin-embedded tissue. J Clin Oncol 2008;26:4966-4972.

216. Rosenwald A, Wright G, Wiestner A, et al. The proliferation gene expression signature is a quantitative integrator of oncogenic events that predicts survival in mantle cell lymphoma. Cancer Cell 2003;3:185-197.

217. Räty R, Franssila $\mathrm{K}$, Joensuu $\mathrm{H}$, et al. Ki-67 expression level, histological subtype, and the International Prognostic Index as outcome predictors in mantle cell lymphoma. Eur J Haematol 2002;69:11-20.

218. Tiemann M, Schrader C, Klapper W, et al. Histopathology, cell proliferation indices and clinical outcome in 304 patients with mantle cell lymphoma (MCL): a clinicopathological study from the European MCL Network. Br J Haematol 2005;131:29-38.

219. Katzenberger T, Petzoldt C, Holler S, et al. The Ki67 proliferation index is a quantitative indicator of clinical risk in mantle cell lymphoma. Blood 2006;107:3407.

220. Johnson NA, Gascoyne RD. Gene expression signatures in follicular lymphoma: are they ready for the clinic? Haematologica 2008;93:982-987.

221. van der Velden VH, Hochhaus A, Cazzaniga G, et al. Detection of minimal residual disease in hematologic malignancies by realtime quantitative PCR: principles, approaches, and laboratory aspects. Leukemia 2003;17:1013-1034.

222. Horsman DE, Gascoyne RD, Coupland RW, et al. Comparison of cytogenetic analysis, southern analysis, and polymerase chain reaction for the detection of $\mathrm{t}(14 ; 18)$ in follicular lymphoma. Am J Clin Pathol 1995;103:472-478.

223. Buckstein R, Pennell N, Berinstein NL. What is remission in follicular lymphoma and what is its relevance? Best Pract Res Clin Haematol 2005;18:27-56.

224. Akasaka T, Akasaka $H$, Yonetani $N$, et al. Refinement of the BCL2/immunoglobulin heavy chain fusion gene in $t(14 ; 18)$ 
(q32; 21 ) by polymerase chain reaction amplification for long targets. Genes Chromosomes Cancer 1998;21:17-29.

225. Weinberg OK, Ai WZ, Mariappan MR, et al. "Minor" BCL2 breakpoints in follicular lymphoma: frequency and correlation with grade and disease presentation in 236 cases. J Mol Diagn 2007;9:530-537.

226. Albinger-Hegyi A, Hochreutener B, Abdou MT, et al. High frequency of $\mathrm{t}(14 ; 18)$-translocation breakpoints outside of major breakpoint and minor cluster regions in follicular lymphomas: improved polymerase chain reaction protocols for their detection. Am J Pathol 2002;160:823-832.

227. van Dongen JJ, Langerak AW, Bruggemann M, et al. Design and standardization of PCR primers and protocols for detection of clonal immunoglobulin and T-cell receptor gene recombinations in suspect lymphoproliferations: report of the BIOMED-2 Concerted Action BMH4-CT98-3936. Leukemia 2003;17:22572317.

228. Summers KE, Goff LK, Wilson AG, et al. Frequency of the Bcl2/IgH rearrangement in normal individuals: implications for the monitoring of disease in patients with follicular lymphoma. J Clin Oncol 2001;19:420-424.

229. Schmitt C, Balogh B, Grundt A, et al. The bcl-2/IgH rearrangement in a population of 204 healthy individuals: occurrence, age and gender distribution, breakpoints, and detection method validity. Leuk Res 2006;30:745-750.

230. Czuczman MS. Controversies in follicular lymphoma: "who, what, when, where, and why?" (not necessarily in that order!). Hematology Am Soc Hematol Educ Program 2006:303-310.

231. Johnson PW, Swinbank K, MacLennan S, et al. Variability of polymerase chain reaction detection of the bcl-2-IgH translocation in an international multicentre study. Ann Oncol 1999;10:1349-1354.

232. Darby AJ, Lanham S, Soubeyran P, Johnson PW. Variability of quantitative polymerase chain reaction detection of the bcl2-IgH translocation in an international multicenter study. Haematologica 2005;90:1706-1707.

233. Corradini P, Astolfi M, Cherasco C, et al. Molecular monitoring of minimal residual disease in follicular and mantle cell nonHodgkin's lymphomas treated with high-dose chemotherapy and peripheral blood progenitor cell autografting. Blood 1997;89:724731.

234. Leonard BM, Hetu F, Busque L, et al. Lymphoma cell burden in progenitor cell grafts measured by competitive polymerase chain reaction: less than one log difference between bone marrow and peripheral blood sources. Blood 1998;91:331-339.

235. Gribben J, Neuberg D, Barber M, et al. Detection of residual lymphoma cells by polymerase chain reaction in peripheral blood is significantly less predictive for relapse than detection in bone marrow. Blood 1994;83:3800-3807.

236. Gribben J, Freedman A, Woo S, et al. All advanced stage non-Hodgkin's lymphomas with a polymerase chain reaction amplifiable breakpoint of bcl-2 have residual cells containing the bcl-2 rearrangement at evaluation and after treatment. Blood 1991;78:3275-3280.

237. Lopez-Guillermo A, Cabanillas F, McLaughlin P, et al. The clinical significance of molecular response in indolent follicular lymphomas. Blood 1998;91:2955-2960.

238. Fernandez-Ruiz E, Cabrerizo M, Ortega M, et al. High molecular response rate and clinical correlation in patients with follicular lymphoma treated with cyclophosphamide-vincristine-prednisone plus interferon alpha 2b. Clin Cancer Res 2003;9:2497-2503.
239. Lambrechts A, Hupkes P, Dorssers L, van't Veer M. Clinical significance of $\mathrm{t}(14 ; 18)$-positive cells in the circulation of patients with stage III or IV follicular non-Hodgkin's lymphoma during first remission. J Clin Oncol 1994;12:1541-1546.

240. Mandigers CM, Meijerink JP, Mensink EJ, et al. Lack of correlation between numbers of circulating t $(14 ; 18)$-positive cells and response to first-line treatment in follicular lymphoma. Blood 2001;98:940-944.

241. Czuczman MS, Grillo-Lopez AJ, McLaughlin P, et al. Clearing of cells bearing the bcl-2 [t(14;18)] translocation from blood and marrow of patients treated with rituximab alone or in combination with CHOP chemotherapy. Ann Oncol 2001;12:109-114.

242. Schmitt C, Balogh B, Grundt A, et al. The bcl-2/IgH rearrangement in a population of 204 healthy individuals: occurrence, age and gender distribution, breakpoints, and detection method validity. Leuk Res 2006;30:745-750.

243. Colombat P, Salles G, Brousse N, et al. Rituximab (anti-CD20 monoclonal antibody) as single first-line therapy for patients with follicular lymphoma with a low tumor burden: clinical and molecular evaluation. Blood 2001;97:101-106.

244. Ghielmini M, Schmitz SF, Cogliatti SB, et al. Prolonged treatment with rituximab in patients with follicular lymphoma significantly increases event-free survival and response duration compared with the standard weekly x 4 schedule. Blood 2004;103:4416-4423.

245. Foran JM, Gupta RK, Cunningham D, et al. A UK multicentre phase II study of rituximab (chimaeric anti-CD20 monoclonal antibody) in patients with follicular lymphoma, with PCR monitoring of molecular response. Br J Haematol 2000;109:8188.

246. Czuczman MS, Grillo-Lopez AJ, White CA, et al. Treatment of patients with low-grade B-cell lymphoma with the combination of chimeric anti-CD20 monoclonal antibody and CHOP chemotherapy. J Clin Oncol 1999;17:268-276.

247. Czuczman MS, Weaver R, Alkuzweny B, et al. Prolonged clinical and molecular remission in patients with low-grade or follicular non-Hodgkin's lymphoma treated with rituximab plus CHOP chemotherapy: 9-year follow-up. J Clin Oncol 2004;22:47114716.

248. Pott C, Boettcher S, Brueggemann $M$, et al. Quantitative assessment of circulating $\mathrm{t}(14 ; 18)$ positive cells by RQ-PCR at diagnosis and follow-up correspond to clinical characteristics and predicts time to treatment failure in follicular lymphoma [abstract]. Blood 2006;108:Abstact 2414.

249. Ladetto M, De Marco F, Benedetti F, et al. Prospective, multicenter randomized GITMO/IIL trial comparing intensive (R-HDS) versus conventional (CHOP-R) chemoimmunotherapy in highrisk follicular lymphoma at diagnosis: the superior disease control of R-HDS does not translate into an overall survival advantage. Blood 2008;111:4004-4013.

250. Hirt C, Schuler F, Kiefer T, et al. Rapid and sustained clearance of circulating lymphoma cells after chemotherapy plus rituximab: clinical significance of quantitative $t(14 ; 18)$ PCR monitoring in advanced stage follicular lymphoma patients. Br J Haematol 2008;141:631-640.

251. Rambaldi A, Carlotti E, Oldani E, et al. Quantitative PCR of bone marrow $\mathrm{BCL} 2 / \mathrm{IgH}+$ cells at diagnosis predicts treatment response and long-term outcome in follicular non-Hodgkin lymphoma. Blood 2005; 105:3428-3433.

252. Gribben J, Neuberg D, Freedman A, et al. Detection by polymerase chain reaction of residual cells with the bcl-2 translocation is associated with increased risk of relapse after 
autologous bone marrow transplantation for B-cell lymphoma. Blood 1993;81:3449-3457.

253. Hirt C, Dolken G. Quantitative detection of $t(14 ; 18)$ positive cells in patients with follicular lymphoma before and after autologous bone marrow transplantation. Bone Marrow Transplant 2000;25:419-426.

254. Freedman A, Gribben J, Neuberg D, et al. High-dose therapy and autologous bone marrow transplantation in patients with follicular lymphoma during first remission. Blood 1996;88:2780-2786.

255. Freedman AS, Neuberg D, Mauch P, et al. Long-term follow-up of autologous bone marrow transplantation in patients with relapsed follicular lymphoma. Blood 1999;94:3325-3333.

256. Brown JR, Feng Y, Gribben JG, et al. Long-term survival after autologous bone marrow transplantation for follicular lymphoma in first remission. Biol Blood Marrow Transplant 2007;13:10571065.

257. Gribben JG, Freedman AS, Neuberg D, et al. Immunologic purging of marrow assessed by PCR before autologous bone marrow transplantation for B-cell lymphoma. N Engl J Med 1991;325:1525-1533.

258. Berinstein NL, Buckstein R, Imrie $\mathrm{K}$, et al. Bcl-2 clearance: optimising outcomes in follicular non-Hodgkin's lymphoma. Bone Marrow Transplant 2002;29(Suppl 1):S14-S17.

259. Galimberti S, Guerrini F, Morabito F, et al. Quantitative molecular evaluation in autotransplant programs for follicular lymphoma: efficacy of in vivo purging by Rituximab. Bone Marrow Transplant 2003;32:57-63.

260. Arcaini L, Montanari F, Alessandrino EP, et al. Immunochemotherapy with in vivo purging and autotransplant induces long clinical and molecular remission in advanced relapsed and refractory follicular lymphoma. Ann Oncol 2008;19:1331-1335.

261. Bottcher S, Ritgen M, Buske S, et al. Minimal residual disease detection in mantle cell lymphoma: methods and significance of four-color flow cytometry compared to consensus IGH-polymerase chain reaction at initial staging and for follow-up examinations. Haematologica 2008;93:551-559.

262. Andersen NS, Donovan JW, Zuckerman A, et al. Real-time polymerase chain reaction estimation of bone marrow tumor burden using clonal immunoglobulin heavy chain gene and bcl$1 / \mathrm{JH}$ rearrangements in mantle cell lymphoma. Exp Hematol 2002;30:703-710.

263. Brizova H, Kalinova M, Krskova L, et al. Quantitative monitoring of cyclin D1 expression: a molecular marker for minimal residual disease monitoring and a predictor of the disease outcome in patients with mantle cell lymphoma. Int J Cancer 2008;123:2865_ 2870.

264. Howard OM, Gribben JG, Neuberg DS, et al. Rituximab and $\mathrm{CHOP}$ induction therapy for newly diagnosed mantle-cell lymphoma: molecular complete responses are not predictive of progression-free survival. J Clin Oncol 2002;20:1288-1294.

265. Pott C, Hoster E, Böttcher S, et al. Molecular remission after combined immunochemotherapy is of prognostic relevance in patients with MCL: results of the randomized Intergroup trials of the European MCL Network [abstract]. Blood 2008;112:Abstract 582.

266. Pott C, Schrader C, Gesk S, et al. Quantitative assessment of molecular remission after high-dose therapy with autologous stem cell transplantation predicts long-term remission in mantle cell lymphoma. Blood 2006;107:2271-2278.
267. Ladetto M, Magni M, Pagliano G, et al. Rituximab induces effective clearance of minimal residual disease in molecular relapses of mantle cell lymphoma. Biol Blood Marrow Transplant 2006;12:1270-1276.

268. Gianni AM, Magni M, Martelli M, et al. Long-term remission in mantle cell lymphoma following high-dose sequential chemotherapy and in vivo rituximab-purged stem cell autografting (R-HDS regimen). Blood 2003;102:749-755.

269. Geisler $\mathrm{CH}$, Kolstad A, Laurell A, et al. Long-term progressionfree survival of mantle cell lymphoma after intensive front-line immunochemotherapy with in vivo-purged stem cell rescue: a nonrandomized phase 2 multicenter study by the Nordic Lymphoma Group. Blood 2008;112:2687-2693.

270. van der Velden VH, Hoogeveen PG, Pieters R, van Dongen JJ. Impact of two independent bone marrow samples on minimal residual disease monitoring in childhood acute lymphoblastic leukaemia. Br J Haematol 2006;133:382-388.

271. Jones D, Kamel-Reid S, Bahler D, et al. Laboratory practice guidelines for detecting and reporting BCR-ABL drug resistance mutations in chronic myelogenous leukemia and acute lymphoblastic leukemia: a report of the Association for Molecular Pathology. J Mol Diagn 2009;11:4-11.

272. Lucio P, Gaipa G, van Lochem EG, et al. BIOMED-I concerted action report: flow cytometric immunophenotyping of precursor B-ALL with standardized triple-stainings. BIOMED-1 Concerted Action Investigation of Minimal Residual Disease in Acute Leukemia: International Standardization and Clinical Evaluation. Leukemia 2001;15:1185-1192.

273. Rawstron AC, Villamor N, Ritgen $M$, et al. International standardized approach for flow cytometric residual disease monitoring in chronic lymphocytic leukaemia. Leukemia 2007;21:956-964.

274. Gabert J, Beillard E, van der Velden VH, et al. Standardization and quality control studies of 'real-time' quantitative reverse transcriptase polymerase chain reaction of fusion gene transcripts for residual disease detection in leukemia - a Europe Against Cancer program. Leukemia 2003;17:2318-2357.

275. van Krieken JH, Langerak AW, Macintyre EA, et al. Improved reliability of lymphoma diagnostics via PCR-based clonality testing: report of the BIOMED-2 Concerted Action BHM4CT98-3936. Leukemia 2007;21:201-206.

276. van der Velden VH, Cazzaniga G, Schrauder A, et al. Analysis of minimal residual disease by $\mathrm{Ig} / \mathrm{TCR}$ gene rearrangements: guidelines for interpretation of real-time quantitative PCR data. Leukemia 2007;21:604-611.

277. van der Velden VH, Wijkhuijs JM, van Dongen JJ. Non-specific amplification of patient-specific Ig/TCR gene rearrangements depends on the time point during therapy: implications for minimal residual disease monitoring. Leukemia 2008;22:6416464164.

278. Croce CM. Oncogenes and cancer. N Engl J Med 2008;358:502_511.

279. Cowland JB, Hother C, Gronbaek K. MicroRNAs and cancer. APMIS 2007;115:1090-1106.

280. Esquela-Kerscher A, Slack FJ. Oncomirs-microRNAs with a role in cancer. Nat Rev Cancer 2006;6:259-269.

281. Calin GA, Sevignani C, Dumitru CD, et al. Human microRNA genes are frequently located at fragile sites and genomic regions involved in cancers. Proc Natl Acad Sci U S A 2004;101:2999_ 3004. 
282. Barbarotto E, Calin GA. Potential therapeutic applications of miRNA-based technology in hematological malignancies. Curr Pharm Des 2008;14:2040-2050.

283. Garzon R, Croce CM. MicroRNAs in normal and malignant hematopoiesis. Curr Opin Hematol 2008;15:352-358.

284. Mi S, Lu J, Sun M, et al. MicroRNA expression signatures accurately discriminate acute lymphoblastic leukemia from acute myeloid leukemia. Proc Natl Acad Sci U S A 2007;104:1997119976.

285. Dixon-McIver A, East P, Mein CA, et al. Distinctive patterns of microRNA expression associated with karyotype in acute myeloid leukaemia. PLoS ONE 2008;3:e2141.

286. Marcucci G, Maharry K, Radmacher MD, et al. Prognostic significance of, and gene and microRNA expression signatures associated with, CEBPA mutations in cytogenetically normal acute myeloid leukemia with high-risk molecular features: a Cancer and Leukemia Group B Study. J Clin Oncol 2008;26:5078-5087.

287. Li Z, Lu J, Sun M, et al. Distinct microRNA expression profiles in acute myeloid leukemia with common translocations. Proc Natl Acad Sci U S A 2008;105:15535-15540.

288. Garzon R, Volinia S, Liu C-G, et al. MicroRNA signatures associated with cytogenetics and prognosis in acute myeloid leukemia. Blood 2008;111:3183-3189.

289. Schotte D, Chau JCK, Sylvester G, et al. Identification of new microRNA genes and aberrant microRNA profiles in childhood acute lymphoblastic leukemia. Leukemia 2008;23:313-322.

290. Kaddar T, Chien WW, Bertrand Y, et al. Prognostic value of miR-16 expression in childhood acute lymphoblastic leukemia relationships to normal and malignant lymphocyte proliferation. Leuk Res 2009; in press.

291. Calin GA, Dumitru CD, Shimizu M, et al. Frequent deletions and down-regulation of micro- RNA genes miR15 and miR16 at
13 q14 in chronic lymphocytic leukemia. Proc Natl Acad Sci U S A 2002;99:15524-15529.

292. Cimmino A, Calin GA, Fabbri M, et al. miR-15 and miR-16 induce apoptosis by targeting BCL2. Proc Natl Acad Sci U S A 2005;102:13944-13949.

293. Calin GA, Cimmino A, Fabbri M, et al. MiR-15a and miR-16-1 cluster functions in human leukemia. Proc Natl Acad Sci U S A 2008;105:5166-5171.

294. Pekarsky Y, Santanam U, Cimmino A, et al. Tcll expression in chronic lymphocytic leukemia is regulated by miR-29 and miR181. Cancer Res 2006;66:11590-11593.

295. Calin GA, Liu C-G, Sevignani C, et al. MicroRNA profiling reveals distinct signatures in B cell chronic lymphocytic leukemias. Proc Natl Acad Sci U S A 2004;101:11755-11760.

296. Calin GA, Ferracin M, Cimmino A, et al. A microRNA signature associated with prognosis and progression in chronic lymphocytic leukemia. N Engl J Med 2005;353:1793-1801.

297. Eis PS, Tam W, Sun L, et al. Accumulation of miR-155 and BIC RNA in human B cell lymphomas. Proc Natl Acad Sci U S A 2005;102:3627-3632.

298. Kluiver J, Poppema S, de Jong D, et al. BIC and miR-155 are highly expressed in Hodgkin, primary mediastinal and diffuse large B cell lymphomas. J Pathol 2005;207:243-249.

299. Lawrie CH, Gal S, Dunlop HM, et al. Detection of elevated levels of tumour-associated microRNAs in serum of patients with diffuse large B-cell lymphoma. Br J Haematol 2008;141:672-675.

300. Lawrie CH, Soneji S, Marafioti T, et al. MicroRNA expression distinguishes between germinal center B cell-like and activated B cell-like subtypes of diffuse large B cell lymphoma. Int J Cancer 2007;121:1156-1161.

301. Rai D, Karanti S, Jung I, et al. Coordinated expression of microRNA-155 and predicted target genes in diffuse large B-cell lymphoma. Cancer Genet Cytogenet 2008;181:8-15. 